\title{
Spatial adaptive responses of highly threatened European mammal species under climate change
}

\author{
Diogo Alagador ${ }^{1 *}$; Jorge Orestes Cerdeira² ${ }^{2}$ Miguel Bastos Araújo ${ }^{13}$ \\ 1- "Rui Nabeiro" Biodiversity Chair, MED: Mediterranean Institute for Agriculture, Environment and Development, \\ Universidade de Évora, Casa Cordovil, $2^{\circ}$ andar, Rua Joaquim Henrique da Fonseca, 7000 - 890 Évora, Portugal. \\ 2- Department of Mathematics, Faculdade de Ciências e Tecnologia da Universidade NOVA de Lisboa, Quinta da \\ Torre, 282 -516 Costa da Caparica, Portugal \\ 3- Department of Biogeography and Global Change, Museo Nacional de Ciencias Naturales, CSIC, Calle José \\ Gutiérrez Abascal, 2, 28006, Madrid, España.
}

Diogo Alagador* corresponding author (alagador@uevora.pt) (ORCID: 0000-0003-0710-3187)

Jorge O. Cerdeira jo.cerdeira@fct.unl.pt (ORCID: 0000-0002-3814-7660)

Miguel B. Araújo mba@uevora.pt (ORCID: 0000-0002-5107-7265)

\begin{abstract}
Current species' range displacements are mostly triggered by climate change but European landscapes are largely dominated by human activities. In this study we identify the most promising spatial adaptive trajectories (SATs) for the thirty most threatened non volant mammal species in Europe up to 2080 (under three climate and land change scenarios) and where/when SATs of each species synchronically converge. We found large contrasts on the persistence of species in SATs, with some species largely reliant on the functionality of areas where many SATs converge. Overall, SATs and convergence centers are not adequately covered by existing conservation areas and coincide with crop and arable lands, compromising species persistence. It is important to invest in the protection of SATs and convergence centers through a mix of conventional instruments and new collaborative forms with the socio-economy. Anticipative plans at long-term coupled with risk analysis offer decision-makers templates to prevent negative surprises.
\end{abstract}

Keywords: Adaptation, Biodiversity, Climate Change, Conservation Planning, Land use, Networks, Optimization, Protected areas 


\section{Spatial adaptive responses of highly threatened European mammal species under climate change}

Current species' range displacements are mostly triggered by climate change but European landscapes are largely dominated by human activities. In this study we identify the most promising spatial adaptive trajectories (SATs) for the thirty most threatened non volant mammal species in Europe up to $\mathbf{2 0 8 0}$ (under three climate and land change scenarios) and where/when SATs of each species synchronically converge. We found large contrasts on the persistence of species in SATs, with some species largely reliant on the functionality of areas where many SATs converge. Overall, SATs and convergence centers are not adequately covered by existing conservation areas and coincide with crop and arable lands, compromising species persistence. It is important to invest in the protection of SATs and convergence centers through a mix of conventional instruments and new collaborative forms with the socioeconomy. Anticipative plans at long-term coupled with risk analysis offer decision-makers templates to prevent negative surprises.

\section{INTRODUCTION}

Local species' extinctions, declining abundance trends and displacements of species from their current range limits are three corollaries of climate change (Chen et al. 2011; Pacifici et al. 2015) which, given time lags on species' responses, may still be a superficial overview of a much bigger issue (Barnosky et al. 2011; Devictor et al. 2012; Menéndez et al. 2006). At the most fundamental level, when species' populations are not able to adapt to the new local climatic conditions, colonization of new suitable areas is the last guarantee of species to persist (Hof et al. 2011; Parmesan 2006). The success of these displacements depends on the interplay between species-specific dispersal rates, climate change velocity, and on the environmental/ecological conditions in the source, the colonizing areas and the regions in between (Brito-Morales et al. 2018; Burrows et al. 2014).

Planning methods capable to predict where, when and how areas are expected to provide important ecological benefits deliver anticipative guidelines to catch opportunities and by-pass bottlenecks such that cost-effective biodiversity conservation solutions are identified (Maxwell et al. 2020; Mokany et al. 2020; Watson et al. 2016). European leaderships have stong scientific backgrounds to carry over effective conservation decisions capable to accommodate the predicted shits of climate and land-use which will modulate European (EU28) landscapes at medium to long-terms.

We take advantage of a recently proposed climate-dedicated spatial conservation planning tool (Alagador et al. 2014, 2016) to assess the aptitude of EU28 landscapes to provide quality habitat for the thirty non-volant mammal species with the largest extinction risk (Table 1) to spatially adapt and persist (up to 2080) to estimated climate and land use changes.

We use spatial adaptive trajectories (SATs) as analytical units in which the persistence of each species up to 2080 is measured (see Methods). A SAT represents a time- ordered sequence of sites (10km $\times 10 \mathrm{~km}$ grid cells in EU28 map), with each site reported to a given time period (baseline, 2020, 2050 and 2080). In each SAT, c, the persistence of a species, $s\left(P_{c}^{S}\right)$, is calculated as the product of the estimated climate suitability scores (in the corresponding sites and time periods) with estimates of species dispersal/colonization success along the sequence of sites in SATs (see Methods). 


\section{\# TABLE 1\#}

Four sets of SATs representing four hypothetical spatial adaptive responses of species were pinpointed. For each species, the unconstrained sets comprehend the 500 SATs offering the largest persistence expectancies $\left(C^{s}\right)$. For each $C^{s}$ the total persistence associated to the whole set was recorded, $P$ s. Because the sites with the largest climatic suitability for a species tend to be clustered, Cs SATs are typically condensed in space with several SATs synchronically converging in the same site at a given period of time. The larger the number of SATs crossing a site $i$ in a time period $t$ (i.e. convergence level $\left.\operatorname{conv} v_{i, t}^{S}\right)$ the more central the site is in the SAT network. The full persistence of a species in $C^{s}$ is therefore largely reliant on the functionality of these convergence centers.

We depicted an alternate set of SATs for each species: a subset of $C^{s}$ SATs $(C / s)$ deprived of convergence centers and in which the overall persistence of species in SATs is maximized $P / s$. The number of SATs in $C / s$ is negatively related with the number of convergence centers in $C^{s}$ and the distribution of $\operatorname{conv}_{i, t}^{s}$. In these cases, $\left.P\right|^{s} \ll P^{s}$, but the functionality of the whole SAT network is not dependent of any central site. In $\mathrm{Cls}$ all the SATs constitute redundant responses of species to climate change, a property that largely favors robustness of SAT networks (Cagua et al. 2019; Williams and Musolesi 2016; Zhan et al. 2017). We also tested two other scenarios in which SATs are made of fixed sites (i.e. discrete, independent populations of a species stationary along time). SATs in $R E F 1^{s}$ are made of the sites likely to best sustain individual species populations over time (i.e. the largest persistence). SATs in $R E F 2^{s}$ are made of sites presenting the largest suitability scores in the baseline time. REF2s mimics a myopic, short-term conservation aptitude in which conservation priority areas for conservation are evaluated based on current status while neglecting future dynamics. In both sets, the persistence of species in each SAT is obtained by the product of site suitability scores through time.

We used three areal attributes to outline the viability of SATs and convergence centers in $C^{s}$ : protected area (PAs) and Natura 2000 (N2k) coverage; extent of urban, arable, forest, crops and grass lands, and; habitat disturbance (Fig. S1). We related the overall species persistence in each SAT set and in singular SATs to those attributes. Assessments were grounded on four time periods (a baseline period, 2020, 2050 and 2080), using three Representative Concentration Pathways related with future climate scenarios (RCP 4.5, 6.0 and 8.5), corresponding land change trajectories and four dispersal success parameterizations (see Methods). Specifically, this study aims to resolve the following questions:

a) Where (distinct sets of) SATs and convergence centers will be located up to 2080? How SATs and convergence centers are characterized in terms of current protection, changing land uses and current habitat disturbance?

b) What is the expected persistence of each species within their optimal SAT sets? Are species persistence largely dependent on the good performance of convergence centers? How conservation areas, land use classes and habitat disturbance levels relate with species persistence scores in SATs?

c) How much dependent are species persistence on dispersal colonization processes?

\section{General patterns of SATs and convergence centers}

The area encompassed by the SATs (either the $C^{s}$ or $C / s$ ) concerning the thirty species covers approximately $600,000 \mathrm{~km}$-sq (20.3\% of EU28, average among scenarios), but merging the solutions obtained in the 12 tested scenarios, the total SAT area 
rise up to approximately $700,000 \mathrm{~km}$-sq (i.e. 23.7\% of the study area) (Fig. 1; for species specific maps see Fig. S3). Therefore, with an extra 100,000 km-sq the areas accommodate the uncertainty associated to the tested climate scenarios and dispersal assumptions (compare Fig. S4-S6).

\section{\# FIGURE 1 \#}

While the great majority of the sites crossed by SATs are useful for only one species (Fig. 1), sites in certain regions offer conditions for up to four species to use them as part of SATs. These sites are scattered along Europe mostly occurring in Western Europe (SW Portugal), the Northern Europe (Finnish boreal forests), the Central Europe (along a large extent of Austria) and the Eastern Europe (in small spots along Slovakia and Romania) (Fig. 1, Fig. S7 \& S8). These same regions also enclose the most important convergence centers measured either by the number of species that a site $i$ constitutes a convergent point at $t$ (Fig. S6) or by the total persistence associated to the SATs of all species crossing $i$ at $t$ (Fig. S9-S10).

\section{Species-specific persistence and levels of SAT convergence}

Only seven species exhibit $P^{s}>250$ (average among scenarios) and, among these, the European pine marten, Martes martes, is the one with the most promising perspectives of successful adaptation to climate change in both $C^{s}$ and $C / s$ SATs $(P s \approx P / s=$ 420-423) (Fig. 2, Fig. 3 \& Fig. S11). There are however five species with low overall persistence scores in $C^{s}$ (i.e. $P^{s}<10$, average among scenarios), three of which with $P l^{s}<1$ (Fig. S11). Generally, $\operatorname{con} v_{i, t}^{s}$ are not related with climate suitability in site $i$ and time period $t$ neither with the persistence scores associated to the SATs crossing $i$ (Fig. S12).

\section{\# FIGURE 2 \#}

For eight species, $C^{s}$ already define an independent set of SATs (Fig. 3 \& Fig. S11) but for 17 species the number of SATs in $\mathrm{C} / \mathrm{s}$ is less than half the number of $\mathrm{C}^{s} \mathrm{SATs}$, with levels of SAT convergence ranging from 7-17 (forest dormouse, Dryomys nitedula) to 164-214 of the Iberian Lynx, Lynx pardinus (Fig. 3, Fig. S11 \& Table 1), depending on the climate x dispersal scenario assessed.

\section{\# FIGURE 3 \#}

\section{Moving versus fixed SATs}

Our results show that some species are largely reliant on spatial displacements to persist up to 2080 (Fig. 2 \& Fig. S5). For example, the persistence of the Iberian lynx, in $R E F 1$ s is 15 times lower than $P$ s. Furthermore, for half of the species persistence in $R E F 2^{s}$ was much lower than in $R E F 1^{s}$, which proofs the large declining rates of climatic suitability in the sites presenting the most favorable climates in the baseline period. 


\section{Protected areas, Natura 2000 and SATs}

Depending on the scenario tested, the whole SATs of the 30 species encompass $20-25 \%$ and $28-33 \%$ of PAs and N2k area in Europe (Fig. S14), respectively.

Only for three species $>20 \%$ of SATs area is enclosed by PAs in some period of time (Fig. S15). These are the northernmost distributed species: the wolverine (41.6\%; in RCP 8.5, D1 scenario), the arctic fox (26.2\%) and the mountain hare, Lepus timidus (21.6\%). Contrarily, SAT coverage by N2k is largely satisfactory (>20\% SAT area) for 14 species (Fig. S16). Important fractions of the climatic suitability characterizing $C^{s}$ and $C / s$ SATs of the Iberian ibex, Capra pyrenaica, and the Iberian lynx are enclosed by N2k (Fig. S17).

A darker picture emerges when conservation area performance is assessed using the persistence outlooks related with their top-persistence SATs rather than on the most common analyses based on areal coverage. Only the Artic fox, the wolverine and the mountain hare, Lepus timidus, present $>10 \%$ of $P^{s}$ within PAs and for the first two species these values largely decrease when referring to the $\mathrm{C} / \mathrm{s}(<2 \% \mathrm{P} / \mathrm{s})$ (Fig. 4). The performance of N2k is less troublesome as it accommodates $>10 \%$ of total persistence of $C^{s}$ SATs of eight species. Similarly, to PAs, persistence coverage of $C / s$ SATs by N2K is greatly reduced (Fig. 3c).

\section{\# FIGURE 4 \#}

For most species both conservation area networks fail to capture the sites with the largest SAT convergence levels (IRR $\approx 1, P$ $<0.05$ ) (Table 1). These alarming results are still reinforced with the unrelatedness of conservation area coverage (for PAs and $\mathrm{N} 2 \mathrm{k}$ ) and the persistence associated to the crossing $C^{s}$ and $\mathrm{Cl}^{\mathrm{s}} \mathrm{SATs}$ (Fig. S18 \& Tables S6).

\section{Land use, habitat disturbance and SATs}

For most species, $C^{s}$ and $C / s$ are characterized by similar land use patterns. Cropland is the dominant land use among the SATs of most species ( $60 \%$ of SATs area, average value). For eight species, SATs in $C^{s}$ match regions of high habitat disturbance (e.g. $\overline{h i i}=53$ for the Egyptian mongoose, Herpestes ichneumon, and the crested porcupine, Histrix cristata). Contrarily, the SATs of the northernmost distributed species (Arctic fox and wolverine) comprehend areas of reduced habitat disturbance, with $\overline{h i i}=5$ and $\overline{h i i}=2$, respectively.

In $\mathrm{Cls}^{\text {s }}$ sets, only forest land coverage relates significantly and positively with single SAT persistence scores for five or more species $\left(n=5 ; \beta_{\text {pers }}=0.05\right)$. Significant negative relationships for five or more species is provided by arable land $\left(n=7 ; \beta_{\text {pers }}=-\right.$ $0.1)$, cropland $\left(n=7 ; \beta_{\text {pers }}=-0.05\right)$ and habitat disturbance, hii $\left(n=5 ; \beta_{\text {pers }}=-0.01\right)$ (Fig. S18\&S19 \& Tables S6).

Only for a restricted number of species land use relates significantly with the occurrence of a convergence point (Table S4\& S7\&S8). Negative relationships with levels of SAT convergence were more prevalent for cropland $\left(\bar{n}=4\right.$, median value; $\bar{\beta}_{\text {conv }}=$ -0.66 to -0.47 , mean values) and habitat disturbance $\left(\bar{n}=5, \bar{\beta}_{\text {conv }}=-0.44\right.$ to -0.36$)$ with sites without the effects of such factors presenting the largest SAT-convergence levels in $C^{s}\left(\bar{\alpha}_{c o n v}=12-16\right.$, mean values among species and 11-32, among time- 
periods) (Table S7). Contrarily, the largest positive relationships with converge levels occur mostly with arable land $(\bar{n}=3$, $\bar{\beta}_{\text {conv }}=0.56$ to 0.66 , for the four time periods), with the highest rates of convergence increase by area covered obtained with grassland $(I R R=3.8-7.0$, average value $)$.

\section{DISCUSSION}

This study provides a comprehensive overview about the location, effectiveness, redundancy and robustness of networks of the SATs of the thirty most threatened non-volant mammal species in EU28 up to 2080. Our results suggest deeply contrasting persistence perspectives among species, with the estimated overall persistence of Cabrerae vole (the less adaptive species) in their $C^{s}$ SATs being $0.3-0.7 \%$ the persistence of the pine marten (the species with the best adaptive prospects). We also evaluated the redundancy of $C^{s}$ SATs by looking into the levels of SAT convergence (max $\left.\operatorname{conv} v_{i, t}^{S}\right)$ in the whole $C^{s}$ sets. Finding independent sets of SATs with the largest overall persistence for a species in $\mathrm{Cls}(P / s)$ allowed us to indirectly correct the overall persistence in $C^{s}\left(P^{s}\right)$ with the integration of the risk of losing convergence centers. We found that although some species present large $P$ s, those values are largely reliant on the functionality of a few sites with large $\operatorname{conv} v_{i, t}^{s} \geq 10$, or a significant number of sites with $1>\operatorname{conv} v_{i, t}^{S}>10$ (see Fig. 2 \& Fig. 3).

Based on $P s, P / s$ and $\operatorname{con} v_{i, t}^{s}$, we were able to depict three groups of species with distinct susceptibility to climate change (i.e. $P^{s}$ and $\left.P / s\right)$ and to the loss of habitat integrity $\left(\operatorname{conv}_{i, t}^{s},\right)($ Fig. 3a). This classification provides an analytical guideline potentially useful to define the management actions needed for an effective protection of species at long-term. The species for which the top-persistence SATs provide large persistence expectancies $\left(P^{s} \geq 100\right)$ and present the lowest convergence levels ( $c o n v_{i, t}^{S}$ <10) (Fig. 3a, nine species in class I) are not significantly impacted by the forecasted climate change rates but the areas defining SATs may still merit conservation attention, such that the whole environmental conditions for species' populations to strive are provided. For these species, reducing local threats along the whole network of SATs turns persistence therein well accounted by the sole effect of climate shifts, as here considered in Eq. 2 (see Methods).

The species with large persistence scores $P$ s that also present large levels of SAT-convergence (Fig. 3a, six species in class II) display a fairly good persistence perspective but are largely dependent on the functionality of a few places, at specific time periods (i.e. convergence centers). Contrarily to the previous group, for which spatio-temporal homogeneous interventions along SATs are appropriate, for the species in this group, safeguarding the full functionality of convergence centers (especially, the most central ones) needs to be particularly enforced to assure that their supportive value subsists by the times SATs are predicted to cross them. Typically, the SATs crossing each convergence centers encompass small and compact regions which facilitates management actions, reduce logistical resources and decrease mid to long-terms costs.

Finally, the species presenting low persistence prospects $P^{s}$ (Fig. 3a, 15 species in class III), are the species that will be severely limited by the sole effect of climate change (i.e. dispersal rates lower than climate change rate). Their low climaterelated persistence scores may still allow some populations to persist for extended periods of time, if finer topographical, hydrological and climatic setups provide suitable conditions for species to survive (this may be especially determinant for small bodied species which may hold in small habitat networks; e.g. the rodent species in this study) (Fordham et al. 2016; Urban 2015; Zellweger et al. 2020). For some species that subsist below minimum viable conditions (i.e. extinction debt), active conservation measures beyond habitat preservation may enlarge the horizons of local persistence (Strassburg et al. 2019; 
Volenec and Dobson 2019). Habitat restoration and assisted colonization may be their last chances to persist. The former interventions need to address not only the full coverage of SATs, but to prioritize efforts in convergence centers (If existing), as the local extinction of species is very much related with the ecological condition on those sites. The areas targeted for assisted colonization need to maintain adequate climatic and habitat conditions at long-term. Noteworthy, the SAT framework here proposed may assist the optimal identification of those areas. Making dispersal success maximal $\left(d_{D(i, j)}^{S}=1\right)$ for the timeperiods when dispersal success between sites $i$ and $j$ is below an acceptable threshold and the colonizing areas $j$ (and their neighboring areas) are likely to present high climatic suitability, the SATs persistence score internalizes the facilitative effect of assisted interventions. Although critical for some species these approaches are not ecologically neutral and require a cautious evaluation on the impacts a new species over native communities (Hunter 2007; Loss et al. 2011; Lunt et al. 2013).

If the great majority of past assessments (covering a myriad of spatial and taxonomic contexts) conclude about the large ineptitude of conservation areas to adequately offset the challenges brought on by current and future rates of climate change over species (Araújo et al. 2011; Heikkinen et al. 2020; Johnston et al. 2013; Monzón et al. 2011), the use of SATs (analytical/conservation units with a spatio-temporal nature) retrieves a still gloomier prospect on the performance of conservation areas (Table 2). This is because: 1) the SATs integrate a temporal dimension which implies that the effectiveness of conservation areas in assisting the protection of SATs is dependent on an extended overview of SATs along time - with large temporal ranges and with high dispersive species, less likely a few fixed conservation areas adequately entangle SATs within their boundaries; 2) the use of persistence scores in SATs to evaluate conservation area effectiveness (instead of sole arealbased metrics) makes the set of SATs heterogeneous in value and therefore turns less likely bounding the top-persistence SATs by conservation areas.

\section{\# TABLE 2 \#}

Aside the climate perspectives characterizing SAT sets (which for many species are already concerning), SAT viability is also dependent on ground attributes. Our results also attest the weak relationship between levels of SAT-convergence and conservation area coverage. Alarmingly, the levels of SAT convergence of two and three species show a negative relationship with PAs and N2k coverage, respectively (median values among 12 climate and dispersal scenarios). This is a particular new finding that supplies conservation area assessments with an inquiry about the timing particular sites emerge as central adaptive points for a particular species and therefore the risks associated to their degradation. When compared to PAs, the greater perspectives delivered by N2k was also obtained in a previous study in EU28 with a much larger taxonomic breadth (Araújo et al. 2011). With $P$ s and $P / s$ dependent of spatially continuous dispersal events, the results obtained in our study steam from the largest area and connectivity of N2k when compared to PAs (Santini et al. 2016; Saura et al. 2018).

The reasonable performance of conservation areas for some species is not a guarantee of future viability in Europe. For most of the analyzed species SATs are largely coincident with crops, arable lands and forests (in EU28 a large fraction are production forests). Preserving high-value habitat for biodiversity requires supportive measures beyond formal conservation areas. Habitat restoration and active legislation and programs to limit threats among unprotected and ecologically-functional lands may provide transient means to safeguard the areas defined by SATs at proper timings (Armsworth and Sanchirico 2008; Huang et al. 2020; Xie et al. 2020). This looks to be especially relevant for one third of the mammal species here analyzed with top-persistence 
SATs located in areas of large anthropic pressure (hii > 40) (Fig. S15) and for the species with sites with largest convergence scores located in areas with habitat disturbance (Table S8).

For implementation purposes a wide set of conservation costs, the flexibility provided by land markets and bio-banking schemes (Salzman et al. 2018) and the conservation value of off-protected areas (Armsworth et al. 2006; Armsworth et al. 2015; Armsworth and Sanchirico 2008) would bring important socioeconomic perspectives to the framework (Naidoo et al. 2006). After the identification of the top-persistence SATs for each species, a multiple-species optimized protocol, capable to accommodate the commonalities associated to the protection of areas suitable for several species while also integrating socioeconomic information, would lead to the reduction of financial requirements, the total area needed and the conflicts with pernicious socioeconomic activities, while ensuring the accomplishment of conservation goals. Optimized area scheduling models using SATs as selection units and species persistence targets were already proposed (Alagador and Cerdeira 2017, 2019). With the present study evidencing the pivotal role of convergence centers for persistence of species, after obtaining optimized solutions for multiple species, a post-processing step of adding into the final solutions the (intra or interspecific) convergence centers considered more advantageous for species (i.e. either because of convergence level, vulnerability to climate change or habitat disturbance) may proof sounding. This step instigates the protection of critical convergence centers and will be particularly easy to consider if they are already well preserved and/or expected to be so in the future (Eaton et al. 2019; Pereira et al. 2017; Rayfield et al. 2011).

With an overview of the most determinant spatial trajectories for species to adapt to plausible scenarios of climate change in EU28 up to 2080 along with the characterization of the sites crossed by those SATs, policy makers may conform their current decisions and actions to the improvement of existing conservation structures (i.e. conservation areas and regulatory measures on land use) and to the reconciliation of biodiversity conservation with human development, thus meeting one pivotal dimension of the new European Green Deal. Aligned with the new European Biodiversity Strategy post-2020 (http://www.alternet.info/outputs/alter-net-eklipse-conf-2019), efforts will need to be made to revise past conservation efforts in EU28 (e.g. PAs and N2k), to supplement them with new conservation areas. Spatial conservation tools need to endorse flexibility and dynamism to solutions such that current and future environmental and socioeconomic challenges are accommodated (D'Aloia et al. 2019). We trust that the SAT framework here proposed might be considered by planners and policy-makers in urgently undertaking taxonomic-comprehensive assessments to identify and appraise the functionality of SATs and high convergence areas in a strategy to set up a Pan-European ecological network resilient to climate change, where, conservation goals, climate mitigation and sustainable economic expectations are maximized.

\section{METHODS}

\section{Biodiversity data and modelling}

We analyzed thirty species which require active conservation efforts at the EU28 scale. Twenty two mammal species of conservation concern, listed in annex IV of Habitats Directive (Directive 92/43/EEC: https:/leur-lex.europa.eu/legalcontent/EN/TXT/?uri=CELEX:31992L0043). For the species in annex IV "a strict protection regime must be applied across their entire natural range within the European Union (EU28), both within and outside Natura 2000 areas". Originally, this annex lists 141 species, but we discarded: (1) marine species (order Cetacea and family Phocidae); (2) volant species (order Microchiroptera and Megachiroptera) given their very specialized habitats, and (3) species with less than 20 occurrence records in The Atlas of European Mammals (Mitchell-Jones et al. 1999). We also added eight species more: Gulo gulo, from annex II 
("their core habitats within European Union should be managed in accordance to their ecological needs"), that is also classified a priority species (an endangered species with a large fraction of its habitats within EU28 limits) and seven species in annex V "member states must ensure that their exploitation and taking in the wild is compatible with maintaining them in a favorable conservation status" - given their current decreasing population trends (following the IUCN Red List:

https://www.iucnredlist.org/). For all but four of the species in analysis (Canis aureus, Hystrix cristata, Mustela putorius and Spermophilus citellus) the climatic suitability within European conservation areas is likely to diminish up until 2080, even under the less drastic change scenarios (Araújo et al. 2011) (Table S1).

The species occurrence data were obtained at the EU28 scale, based on The Atlas of European Mammals, at $50 \mathrm{~km} \times 50 \mathrm{~km}$ grid cells. We collected bioclimatic data to reflect the averaged baseline conditions (1960-1990). The selected bioclimatic variables reflect a large component of the energy-water requirements (extreme values and seasonality) of a wide set of mammal species (Maiorano et al. 2011; Morán-Ordóñez et al. 2017): annual-seasonality of temperature (SD, ${ }^{\circ} \mathrm{C}$ ); annual accumulated precipitation $(\mathrm{mm})$; mean temperature of the coldest quarter $\left({ }^{\circ} \mathrm{C}\right)$ and mean precipitation of the driest quarter $(\mathrm{mm})$. However, because there is surprisingly little experimental work for any particular species to guide the choice of bioclimatic limiting variables, the variables are generic and represent a hypothetical minimum basic set to undertake nichebased modeling at the EU28 scale. Climate data were obtained from CHELSA (Karger et al. 2017, http://chelsa-climate.org/) at 30-arsec edge resolution (approx. $1 \mathrm{~km}$-sq). For model calibration (matching occurrence data) and projection, data were rescaled to $50 \mathrm{~km} \times 50 \mathrm{~km}$ and 10-arcmin x 10-arcmin grid cell resolution, respectively, using area-weighted averaging.

We used biomod2 (Thuiller et al. 2009), a package in CRAN-R (https://cran.r-project.org/), to fit seven species distributions models (SDMs) (Artificial Neural Networks; Boosted regression Trees; Classification Trees; Flexible Discriminant Analysis; Generalized Additive Models; Generalized Linear Models and Surface Range Envelopes) for each species. The climatic predictors were standardized into a zero-one scale. Models were calibrated using ten random samples made of $80 \%$ occurrence data and evaluated on the remaining $20 \%$ using the model-specific default parameters in biomod2. For each run, five random samples of pseudo-absences were obtained with the number of pseudo-absences being the lowest between ten times the number of species' occurrences or 1,145 (half of the total number of grid cells in the atlases "European" maps). Models with True Skill Statistic (TSS) values below 0.5 were discarded from further analysis (Table S2).

In order to evaluate the effects of climate change, current and future predictions (1991-2020, referred 2020; 2021-2050, referred 2050, and; 2051-2080, referred 2080) of the four bioclimatic variables were obtained from a new generation of five global circulation models (GCMs) included in the Coupled Model Intercomparison Project Phase 5 (CMIP5, Taylor et al. 2011) (CSCM4, GFDL-CM3, HadGEM2-climate change, INMCM4 and MIROC5) (for acronyms and description see Scoccimarro et al. 2013). The GCMs were selected as they cover a remarkable variability in terms of global future climate outlooks (Sanderson et al. 2015). Predictions were made for three representative concentration pathways (RCPs), representing a decreasing gradient of global climate change mitigation efforts by 2100 - RCP4.5, RCP6 and RCP8.5 - based on the Fifth Assessment Report (AR5) from the Intergovernmental Panel on Climate Change (IPCC) (Moss et al. 2010). Calibrated with baseline period data (see above), the SDMs were ran with the bioclimatic projections for each time period x GCM x RCP combination. For baseline period and each RCP projection, we obtained a TSS-weighted consensus map based on the seven modelling techniques. For current and future time periods $x$ RCP, final consensus projections were made after averaging the "TSS-weighted maps" among the five GCMs. 
In order to remove effects of sample size when comparing models for species with distinct prevalence, we corrected suitability values using the favorability function (Acevedo and Real 2012). Favorability describes the deviation of local suitability for a species from what it would be expected by its prevalence. As a result, favorability values higher than 0.5 occur where local conditions favor the presence of the species. For convenience, we keep designating by suitability the favorability scores obtained for each species.

In the baseline period, where a species occurrence was not recorded the corresponding suitability score was set to zero. For future time periods, to overcome plausible situations of species being recorded in sink (non-viable) areas, we defined unsuitable in all the time periods the $10 \mathrm{arcmin} \times 10$ arcmin grid cells (henceforth sites) with suitability projections lower than the $10^{\text {th }}$ percentile score obtained in baseline period among the sites nested in the $50 \mathrm{~km} \times 50 \mathrm{~km}$ grid cells with species records (i.e. atlas data). Henceforth, suitability score of species $s$ in site $i$ at time $t$ is referred as $o_{i, t}^{S}$.

A model of dispersal success $\left(d_{D}^{S}\right)$ related to the geographic distance between a source and colonizing site, $D$, was built for each species, $s$, using dispersal rate information from Schloss et al. (2012). For the species with no information, we estimated dispersal rates by averaging dispersal rates of taxonomically-similar species, with body weight on the same order of magnitude. We calibrated $D_{\max }^{s}$ to reflect the distance the species $s$ is able to disperse in 30 yrs (Table S3; Fig.S2). Alongside median dispersal rates, we also accounted for possible long-distance dispersal events using $D_{\text {max }}^{\prime s}=1.5 \times D_{\max }^{s}$. For each of the 30 species, we used the same simplified exponential decaying function over geographic distance (Eq.1), assuming that suitable climates and habitats for the establishment, survival, and reproduction of populations will exist between the source and the receptor areas, along the $30 \mathrm{yrs}$ interval between time slices (i.e. the dispersal periods) and that populations will disperse directly into the closest suitable receptor site.

$\begin{cases}d_{D}^{S}=\exp \left(-\alpha \cdot \frac{D}{D_{\text {max }}^{S}}\right) & , D \leq D_{\text {max }}^{S} \\ d_{D}^{S}=0 & , D>D_{\text {max }}^{S}\end{cases}$

The measure of dispersal success ranges from zero to one. We parameterized $\alpha$ to produce two settings of dispersal success corresponding to $d_{D \max }^{s}=0.05$ and $d_{D \max }^{s}=0.025$ (i.e. in 1000 dispersal events from the source to a receptor site distancing $D_{\max }^{S}$, only 50 and 25 events result in a successful established colonization, respectively).

All the analyses were performed crossing both the three RCPs and the four dispersal assumptions (made by intersecting the two $D_{\max }^{S}$ and the two $\alpha$ parameterizations).

\section{Spatial adaptive trajectories}

We used the dispersal corridor concept proposed in Alagador et al. (2014) to represent the spatial adaptive trajectories (SATs) of species (i.e. the spatial displacements of local populations of species along time). A SAT is an ordered set of sites $c=$ $\left(i_{0}, i_{1}, \ldots, i_{T}\right)$, where each site corresponds to one period of time. An index of persistence for a species $s$ in a SAT $c\left(P_{c}^{S}\right)$ was settled using two ecological descriptors which modulate the spatial responses of species to climate change, i.e. local climatic suitability and dispersal success:

$P_{c}^{S}=o_{i_{0}}^{S} \times d_{D\left(i_{0}, i_{1}\right)}^{S} \times o_{i_{1}}^{S} \times d_{D\left(i_{1}, i_{2}\right)}^{S} \times \ldots \times d_{D\left(i_{T-1}, i_{T}\right)}^{S} \times o_{i_{T}}^{S}$ 
where SAT $c$ is made by the sites $i_{0}, i_{1}, \ldots, i_{T}$ referenced to the time-periods $0,1, \ldots, T$, respectively; $o_{i_{t}}^{S}$ is the estimated suitability in site $i$, for species $s$, during time-period $t$ (suitability increases in a zero to one range); $D(i, j)$ refers to the distance between sites $i$ and $j$ (geographic distance herein), and $d_{D(i, j)}^{s}$ defines the dispersal success of species $s$ (Eq. 1). Note that a SAT may be comprised by a single site used along all the time periods analyzed (i.e. $i_{0}=i_{1}=\ldots=i_{T}$ ). In this case, $d_{D(i, i)}^{S}=1$ (Eq.1). Potentially, $P_{c}^{s}$ ranges from zero, when at least one of the factors in the product is zero, to one, when local suitability and dispersal success along the SAT are repetitively maximum (i.e. one). It is worth noting that i) the persistence index $P_{c}^{s}$ can be calculated using the information provided in the more commonly available data (i.e. local suitability predictions derived from SDMs and dispersal success obtained from empirical or experimental dispersal kernels); and ii) if $o_{i_{t}}^{S}$ and $d_{D}^{S}$ refer to true probabilities, $P_{c}^{s}$ can be interpreted as the probability of success of a population of species $s$ to persist along the SAT $c$, from a baseline time period until $T$.

For each species, we identified the 500 different SATs with the largest persistence scores using the algorithm developed by Martins et al. (1999). The selection of SATs was made for each combination of three RCPs (cl $\in\{R C P 4.5, R C P 6.0, R C P 8.5\}$ ) and four dispersal scenarios ( $d p \in\{D 1, D 2, D 3, D 4\}$ ) (Fig. S2), thus leading to 12 sets of the 500 top-persistence SATs determined for each species $s, C^{s}(c l, d p)$. The selection of 500 SATs for each species was made under the rationale that, 500 is a sufficient number to grasp SATs where persistence scores are significantly different from zero, such to provide minimum guarantees of success (Fig. S13). In species-centered studies, the number of SATs to select could depend on the exact number of SATs providing a minimum guarantee of success for a species. For the species for which fewer than 500 SATs with no-null persistence scores exist, we identified the maximum number available (to simplify, we refer to 500 to represent both of the cases).

\section{Independent spatial adaptive trajectories}

Given the spatial auto-correlated nature of geophysical processes (e.g. climate) and, consequently, of environmental suitability for a species (e.g. climatic suitability), it is likely that, among the set of high persistence SATs for a species [ $\left.C^{s}(c l, d p)\right]$, some cross adjacent areas and, in some cases, converge in a site in one (or more) periods of time. The habitats within these synchronically converging sites are particularly important to protected because they are central points for the successful adaptation of a species to climate change. In the case of severe degradation of a single site where several SATs meet, the perspectives of a full realized adaptive response of a species may be severely compromised. Because the extent of failure is related with the number of SATs synchronically concentrating in a site, we thus introduce a measure of the convergence level of site $i$ at time period $t\left[\operatorname{conv}_{i, t}^{S}(c l, d p)\right]$, as the number of SATs in $C^{s}(c l, d p)$ that intersect at site $i$ in time period $t$. High values of $i_{t}^{s}(c l, d p)$ indicate that $i$ is a pivotal area for species $s$ persistence in, at least, time period $t$. We also define the convergence level of the whole set of SATs, $C^{s}(c l, d p)$ to be largest convergence level among all sites and all time-periods, i.e. max $\operatorname{conv}^{s}(d l, d p)=\max _{\{i, t\}} \operatorname{conv}_{i, t}^{s}(c l, d p)$. Note that in any set of independent SATs for a species $s, \max c o n v^{s}(c l, d p)=1$, while for an unconstrained set of 500 SATs, $\max \operatorname{conv} s(c l, d p)=500$.

When two SATs converge in a site in a same time period, we say the SATs are dependent. If a set of SATs is independent (i.e., has no two dependent SATs), the sum of persistence of all SATs with respect to the same species $s$ can be interpreted as the expected number of single populations of the species that will persist in a given time horizon. It is therefore relevant to identify 
for each species a subset $C / s(c l, d p)$ of independent SATs of $C^{s}(c l, d p)$ for which the sum of persistence scores is maximum, and compare the overall persistence of $C^{s}(c l, d p)$ :

$P^{s}(c l, d p)=\sum_{c \in C^{s}(c l, d p)} P_{c}^{s}$

with the overall persistence of $\mathrm{Cls}(c l, d p)$ :

$P I^{s}(c l, d p)=\sum_{c \in C I^{s}(c l, d p)} P_{c}^{s}$,

while also accounting for the fraction of SATs in $C^{s}(c l, d p)$ that are retained in $C^{s}(c l, d p)$, i.e. $|C l s(c l, d p)| / 500$, in the present case-study. Table 3 summarizes the meaning of the different symbols introduced above.

From here on, when no ambiguity exist we simply notation by excluding the reference to the climate and dispersal combination used (i.e. cl,dp).

\section{\# TABLE 3 \#}

\section{Fixed population adaptive trajectories}

In order to assess the benefits of providing good quality habitats along the SATs expected to carry optimal climatic conditions for species to naturally adapt climate change, we compared the persistence expectancies, $P$ s, related with $C^{s}$, with the persistence expectancies in two types of referential SAT sets, both characterized by assuming populations fixed along time (i.e. $i_{0}=i_{1}=i_{2}=i_{3}=j$, in Eq.2). One such referential set is made of the 500 fixed SATs that provide the largest persistence scores (REF1s). The other set is made of the 500 SATs using the most suitable sites in baseline period (REF2s). Both, the persistence scores associated to each SAT and to whole set of SATs in each of these referential sets were contrasted with the respective scores persistence scores $P_{C}^{S}$ and $P^{S}$. We also obtained similar referential sets to contrast with the independent set of SATs, $C /$ s. They are subsets $R E F 1^{s}$ and $R E F 2^{s}$, with the number of SATs equal to the size of $C /$ s.

\section{Land use, habitat degradation and conservation areas}

We characterized the European landscape using land-use classes, a gradient of habitat degradation and the location of conservation areas (i.e. PAs \& N2k) (Fig. S1). We used data from the ALARM project (Settele et al. 2012; Settele et al. 2005; Spangenberg 2007) to obtain spatial projections of land-use classes in baseline and 2020, 2050 and 2080. Although, more recent land-use projections exist (e.g. Land Use Harmonization, http://luh.umd.edu), their coarser resolution and global emphasis made us to opt for the European-based, $250 \mathrm{~m} \times 250 \mathrm{~m}$ resolution ALARM dataset. Given that ALARM projections were established using the emissions scenarios developed in IPCC's AR4, we realigned them to the more recent AR5 RCPs. 
Following Rogelj et al. (2012) and Spangenberg et al. (2012) the scenario of maximum land use change (GRAS: GRowth Applied Strategy), stemming from the most severe A1FI scenario, was matched with RCP8.5; the moderate change scenario (BAMBUSEL: Business As Might Be Usual followed by a Shock in Energy-price Level), covering the A2 scenario, was matched with RCP6 and the lowest land use change scenario (SEDG, Sustainable-Europe Development Goal), derived from B1, matched the RCP4.5. The ALARM land-use data follow the CORINE classification system (see https://land.copernicus.eu/paneuropean/corine-land-cover/view). Land in each site is catalogue either as build-up (urban land), arable land, forest land, grassland, permanent crops and others. Given the indistinct character of the "others" class we opted to discard it out from analysis. We obtained the percentage of each original 10-arcmin x 10-arcmin site covered by each of land-use class.

We used the newest human footprint index 2.0 (hii) (Venter et al. 2016, available at https://wcshumanfootprint.org/) as a measure of local anthropic disturbance derived from either direct and indirect human intervention over the landscape. The original $1 \mathrm{~km} \times 1 \mathrm{~km}$ site data were averaged to 10-arcmin edge-site scale to match species' data. The original hii values range from zero to 50 , but we standardized hii into a zero to 100 range, to pair the percentage units used in the remaining variables analyzed (Fig. S1). The largest hii values represent areas of highly artificialized (degraded) habitats.

We analyzed two spatial conservation templates in Europe. The N2k, the centerpiece of EU28 nature and biodiversity policy, is a wide network of nature protection areas established under the 1992 Habitats Directive, to support the long-term survival of Europe's most valuable and threatened species and habitats. We obtained georeferenced information for N2k from the web page of the European Environment Agency (available at https://www.eea.europa.eu/data-and-maps/data/natura-11; date 7 March 2019). Data regarding PAs were downloaded from the World Database on Protected Areas website (available at (https://www.protectedplanet.net/; date: 7 March 2019). We limited the analyzes to the I-IV IUCN categories, as these are presumed to be the ones with the highest mandates to protect biodiversity therein. We mapped polygon data and point data PAs, with boundaries for the latter assuming a circular shape, centered on the original point and spanning the referenced area. We merged polygon and circular areas in a final PAs map. We measured the fraction of each site covered by each of these conservation schemes (Fig. S1).

\section{Spatial analyzes}

For each species, we mapped $C^{s}$ and $C /$, respecting each of the three RCPs $x$ four dispersal scenario combinations. For each of the SAT sets, we: 1) evaluated the frequency selection of each site, among the 12 scenarios tested (for each time-period in analysis and for all periods together); 2) counted the number of species using SATs crossing each site (in each time period and all together); 3) summed (overall) persistence scores associated to the SATs that cross each site to produce a map reflecting the total persistence benefit carried by each site (for each species and all together); 4) mapped the convergence levels, max convs, of all sites in Europe, (for each species and all species together), and 5) assessed the spatial stability of SATs across time, measuring the average number of time periods each site is used by SATs (averages obtained among the four dispersal scenarios for each RCP).

We then overlaid all these maps with the spatial distribution of land-use classes (percentage coverage), current habitat disturbance (i.e. human footprint index) and conservation areas (percentage coverage) (referred as spatial attributes, see below). We tested about significant relationships between each habitat predictor and persistence scores in the SATs selected for each of the species ( $\beta_{\text {pers: }}$ regression slope). 
We also performed a univariate regression analysis to infer about the relationships between the spatial attributes, persistence scores associated to crossing SATs and convergence levels associated to each site and the number of times, among the tested runs (i.e. frequency selection), the site emerged as a priority among the highlighted SATs for the whole set of species ( $\beta_{\text {reqeq }}$ : regression slope) (Table S5).

For each species, the relationships between the number of converging SATs in each point $\left(\operatorname{conv}_{i, t}^{s}\right)$ and spatial attributes were tested in two steps. First, differences in the distribution of each of the habitat factors among sites crossed by a single SAT, $\operatorname{conv}_{i, t}^{S}=1$ in a given time-period $t$ and sites crossed by more than one SAT in the same time-period $\operatorname{conv}_{i, t}^{S}>1$ were tested using Wilcoxon signed-rank tests with the strictly standardized mean difference as effect size. Second, the relationship between the spatial attributes among the sites with $\operatorname{conv}_{i, t}^{s}>1$ was analyzed using zero-truncated generalized linear model with a $\log$ link-function (i.e. Poisson models, $\alpha_{\text {convv: }}$ the intersect value; $\beta_{\text {convv: }}$ regression slope; IRR: incidence ratio rate, i.e. the average increase on the number of SATs crossing each site, with one-unit increase of each attribute). Statistical analyses were performed in CRAN-R using Im function for linear regression models, the wilcox.test function for Wilcoxon tests and the vglm for the one-truncated Poisson models.

Finally, we quantified the sensitivity of: (1) levels of SAT-convergence, $\operatorname{conv}_{i, t}^{s}$, (2) land-use class coverage, (3) the human footprint index, (4) conservation area coverage, (5) the overall species persistence in the different SAT sets (i.e. $\left.C^{s}, C / s\right)$, and (6) location of SATs, to variation of RCP and dispersal scenarios, independently (Fig. S21-24).

\section{Simplifying assumptions and analytic caveats}

A number of caveats need to be highlighted in this study. First, results are affected by the general limitations of species distribution modelling (SDMs) (Guisan and Thuiller 2005). They: (1) miss meaningful information about local population dynamics, abundance, population structure, and local extinction risk; (2) neglect the inherent effect of humans on the equilibrium of species to climate (Faurby and Araújo 2018); (3) miss information about the biotic interactions and how these will modify with changing climates (non-analog communities)(Keith et al. 2009); (4) are immersed in large uncertainties concerning the structure of species' niches (which variables best explain species occurrences? which models best translate those responses?) (Sax et al. 2013). In the future, a better understanding and narrowing of uncertainties will be critical for the utility of suitability maps in decision-making for multiple species.

Second, species occurrences and climate data used to build SDMs were coarse-resolute (i.e. $50 \mathrm{~km} \times 50 \mathrm{~km}$ ) and therefore miss accurate species/climate matchings within sites, thus leading to underestimations of bioclimatic niches. Furthermore, the large resolute $(1 \mathrm{~km} \times 1 \mathrm{~km})$ climate data used for projecting climatic suitability for the thirty species were derived from statistical top-down interpolations that miss the contextual topographic, edaphic and hydrological factors determining climatic patterns and species occurrence potential at very local scales (Lenoir et al. 2017; Pateman et al. 2015; Potter et al. 2013). Additionally, landuse was characterized by six classes which do not clearly define management intensity and levels of habitat disturbance (e.g. distinction between production and semi-natural forestry, agriculture and livestock, etc.). Predictions on land-use evolution for the recent future are largely uncertain and exposed to unpredicted multi-scaled policy decisions (Pontius and Neeti 2009; Popp et al. 2017). With these shortcomings in mind, we opted by undertaking the analyzes using the best available data coherently available for the whole EU28 region. In deepest analyses oriented for implementation purposes, finer and coherent sets of data would provide more robust support. 
Third, SAT evaluation is largely reliant on knowledge about dispersal and colonization processes. Accurate data reflecting the main stages compounding dispersal and colonization processes (i.e. emigration, movement, establishment and proliferation events) are seldom available (Lester et al. 2007; Schloss et al. 2012) and there is no taxonomic homogeneity around the traits involved in such mechanisms (Estrada et al. 2016). We accommodated these complexities using simplified dispersal kernel functions based on linear distances between source and colonizing areas rather than on (ideal) functional distances that are very specific among species and space. The persistence metrics associated to SATs assume that dispersal success is independent from colonizing areas. This simplification allowed the analyzes to by-pass the elaborated interactions among those two events, which generate complexities hard to tackle.

Fourth, increasing the number of time-periods to be analyzed along with finer resolute data would better characterize the spatiotemporal continuum that is intrinsic to SATs. Seasonal variability and weather conditions may largely determine the adaptive opportunities of species and the resilience of species' populations at long-term. Relatedly, in many regions, the variability of microclimates along space greatly exceeds the magnitude of climate change. Ignoring this variability leads to erroneous predictions of climate change impacts on species distributions and, consequently, on important pathways deemed critical for permanent or transitory settlement of species population when responding to climate change (Lenoir 2020; Lenoir et al. 2017; Zellweger et al. 2020). Coarse-scaled assessments may therefore miss underseen opoortunities for successful adaptive responses of species and may assume bottlenecks in regions which, at microscales, embody suitable conditions for species survival (Baker et al. 2017).

Finally, it is not obvious on how to measure the persistence of a species in several SATs when these are not independent, Several studies have provided evaluations about the centrality of areas within spatial networks of populations (Rozenfeld et al. 2008), individual habitat use (Pereira et al. 2017; Saura and de la Fuente 2017) or PA systems (Chadès et al. 2011), but their experiments do not provide a persistence based measuring associated to the loss of such areas. With such a gap, the framework here introduced relates $P^{s}$ with $\left.P\right|^{s}$ while accounting for $\max \operatorname{con} v_{i, t}^{S}$, such to integrate the putative effects of loss of central sites over the persistence of a species in $C^{s} s$. A fine-tuned parameterization on the relationship between these measures is needed and depends on well-designed experimental studies.

\section{ACKNOWLEDGEMENTS}

This work was funded by national funds through the Fundação para a Ciência e a Tecnologia (FCT) under the project UIDB/05183/2020 and also by FEDER funds and Programa Operacional Factores de Competitividade - COMPETE — through FCT's project PTDC/AAG-GLO/3979/2014 (ref. 9471-RIDTI).

\section{REFERENCES}

Acevedo, P., Real, R., 2012. Favourability: concept, distinctive characteristics and potential usefulness. Naturwissenschaften 99, 515-522.

Alagador, D., Cerdeira, J.O., 2017. Meeting species persistence targets under climate change: A spatially explicit conservation planning model. Diversity and Distributions 23, 703-713. 
Alagador, D., Cerdeira, J.O., 2019. Introducing Spatio-Temporal Conservation Units: Models for Flexible Optimization of Species Persistence Under Climate Change, In Handbook of Climate Change and Biodiversity. eds W. Leal Filho, J. Barbir, R. Preziosi, pp. 243-258. Springer International Publishing, Cham.

Alagador, D., Cerdeira, J.O., Araújo, M.B., 2014. Shifting protected areas: scheduling spatial priorities under climate change. Journal of Applied Ecology 51, 703-713.

Alagador, D., Cerdeira, J.O., Araújo, M.B., 2016. Climate change, species range shifts and dispersal corridors: an evaluation of spatial conservation models. Methods in Ecology and Evolution 7, 853-866.

Araújo, M.B., Alagador, D., Cabeza, M., Nogués-Bravo, D., Thuiller, W., 2011. Climate change threatens European conservation areas. Ecology Letters 14, 484-492.

Armsworth, P.R., Daily, G.C., Kareiva, P., Sanchirico, J.N., 2006. Land market feedbacks can undermine biodiversity conservation. Proceedings of the National Academy of Sciences of the United States of America 103, 5403-5408.

Armsworth, P.R., Larson, E.R., Jackson, S.T., Sax, D.F., Simonin, P., Blossey, B., Green, N., Klein, M.L., Lester, L., Ricketts, T.H., Runge, M.C., Shaw, M.R., 2015. Are conservation organizations configured for effective adaptation to global change? Frontiers in Ecology and the Environment 13, 163-169.

Armsworth, P.R., Sanchirico, J.N., 2008. The effectiveness of buying easements as a conservation strategy. Conservation Letters 1, 182189.

Baker, D.J., Hartley, A.J., Pearce-Higgins, J.W., Jones, R.G., Willis, S.G., 2017. Neglected issues in using weather and climate information in ecology and biogeography. Diversity and Distributions 23, 329-340.

Barnosky, A.D., Matzke, N., Tomiya, S., Wogan, G.O.U., Swartz, B., Quental, T.B., Marshall, C., McGuire, J.L., Lindsey, E.L., Maguire, K.C., Mersey, B., Ferrer, E.A., 2011. Has the Earth's sixth mass extinction already arrived? Nature 471, 51-57.

Brito-Morales, I., García Molinos, J., Schoeman, D.S., Burrows, M.T., Poloczanska, E.S., Brown, C.J., Ferrier, S., Harwood, T.D., Klein, C.J., McDonald-Madden, E., Moore, P.J., Pandolfi, J.M., Watson, J.E.M., Wenger, A.S., Richardson, A.J., 2018. Climate Velocity Can Inform Conservation in a Warming World. Trends in Ecology \& Evolution 33, 441-457.

Burrows, M.T., Schoeman, D.S., Richardson, A.J., Molinos, J.G., Hoffmann, A., Buckley, L.B., Moore, P.J., Brown, C.J., Bruno, J.F., Duarte, C.M., Halpern, B.S., Hoegh-Guldberg, O., Kappel, C.V., Kiessling, W., O/'Connor, M.I., Pandolfi, J.M., Parmesan, C., Sydeman, W.J., Ferrier, S., Williams, K.J., Poloczanska, E.S., 2014. Geographical limits to species-range shifts are suggested by climate velocity. Nature $507,492-495$.

Cagua, E.F., Wootton, K.L., Stouffer, D.B., 2019. Keystoneness, centrality, and the structural controllability of ecological networks. Journal of Ecology 107, 1779-1790.

Chadès, I., Martin, T.G., Nicol, S., Burgman, M.A., Possingham, H.P., Buckley, Y.M., 2011. General rules for managing and surveying networks of pests, diseases, and endangered species. Proceedings of the National Academy of Sciences 108, 8323.

Chen, I.-C., Hill, J.K., Ohlemüller, R., Roy, D.B., Thomas, C.D., 2011. Rapid range shifts of species associated with high levels of climate warming. Science 333.

D'Aloia, C.C., Naujokaitis-Lewis, I., Blackford, C., Chu, C., Curtis, J.M.R., Darling, E., Guichard, F., Leroux, S.J., Martensen, A.C., Rayfield, B., Sunday, J.M., Xuereb, A., Fortin, M.-J., 2019. Coupled Networks of Permanent Protected Areas and Dynamic Conservation Areas for Biodiversity Conservation Under Climate Change. Frontiers in Ecology and Evolution 7. 
Devictor, V., van Swaay, C., Brereton, T., Brotons, L., Chamberlain, D., Heliola, J., Herrando, S., Julliard, R., Kuussaari, M., Lindstrom, A., Reif, J., Roy, D.B., Schweiger, O., Settele, J., Stefanescu, C., Van Strien, A., Van Turnhout, C., Vermouzek, Z., WallisDeVries, M., Wynhoff, I., Jiguet, F., 2012. Differences in the climatic debts of birds and butterflies at a continental scale. Nature Clim. Change 2, 121-124.

Eaton, M.J., Yurek, S., Haider, Z., Martin, J., Johnson, F.A., Udell, B.J., Charkhgard, H., Kwon, C., 2019. Spatial conservation planning under uncertainty: adapting to climate change risks using modern portfolio theory. Ecological Applications 29, e01962.

Estrada, A., Morales-Castilla, I., Caplat, P., Early, R., 2016. Usefulness of Species Traits in Predicting Range Shifts. Trends in Ecology \& Evolution 31, 190-203.

Faurby, S., Araújo, M.B., 2018. Anthropogenic range contractions bias species climate change forecasts. Nature Climate Change 8, 252256.

Fordham, D.A., Brook, B.W., Hoskin, C.J., Pressey, R.L., VanDerWal, J., Williams, S.E., 2016. Extinction debt from climate change for frogs in the wet tropics. Biology Letters 12.

Guisan, A., Thuiller, W., 2005. Predicting species distribution: offering more than simple habitat models. Ecology Letters 8, 993-1009.

Heikkinen, R.K., Leikola, N., Aalto, J., Aapala, K., Kuusela, S., Luoto, M., Virkkala, R., 2020. Fine-grained climate velocities reveal vulnerability of protected areas to climate change. Scientific Reports 10, 1678.

Hof, C., Levinsky, I., Araújo, M.B., Rahbek, C., 2011. Rethinking species' ability to cope with rapid climate change. Global Change Biology $17,2987-2990$.

Huang, J.-L., Andrello, M., Martensen, A.C., Saura, S., Liu, D.-F., He, J.-H., Fortin, M.-J., 2020. Importance of spatio-temporal connectivity to maintain species experiencing range shifts. Ecography 43, 591-603.

Hunter, M.L., 2007. Climate Change and Moving Species: Furthering the Debate on Assisted Colonization. Conservation Biology 21, 13561358.

Johnston, A., Ausden, M., Dodd, A.M., Bradbury, R.B., Chamberlain, D.E., Jiguet, F., Thomas, C.D., Cook, A.S.C.P., Newson, S.E., Ockendon, N., Rehfisch, M.M., Roos, S., Thaxter, C.B., Brown, A., Crick, H.Q.P., Douse, A., McCall, R.A., Pontier, H., Stroud, D.A., Cadiou, B., Crowe, O., Deceuninck, B., Hornman, M., Pearce-Higgins, J.W., 2013. Observed and predicted effects of climate change on species abundance in protected areas. Nature Clim. Change 3, 1055-1061.

Karger, D.N., Conrad, O., Böhner, J., Kawohl, T., Kreft, H., Soria-Auza, R.W., Zimmermann, N.E., Linder, H.P., Kessler, M., 2017. Climatologies at high resolution for the earth's land surface areas. Scientific Data 4, 170122.

Keith, S.A., Newton, A.C., Herbert, R.J.H., Morecroft, M.D., Bealey, C.E., 2009. Non-analogous community formation in response to climate change. Journal for Nature Conservation 17, 228-235.

Lenoir, J., 2020. Rethinking climate context dependencies in biological terms. Proceedings of the National Academy of Sciences, 202016537.

Lenoir, J., Hattab, T., Pierre, G., 2017. Climatic microrefugia under anthropogenic climate change: implications for species redistribution. Ecography 40, 253-266.

Lester, S.E., Ruttenberg, B.I., Gaines, S.D., Kinlan, B.P., 2007. The relationship between dispersal ability and geographic range size. Ecology Letters 10, 745-758.

Loss, S.R., Terwilliger, L.A., Peterson, A.C., 2011. Assisted colonization: Integrating conservation strategies in the face of climate change. Biological Conservation 144, 92-100. 
Lunt, I.D., Byrne, M., Hellmann, J.J., Mitchell, N.J., Garnett, S.T., Hayward, M.W., Martin, T.G., McDonald-Maddden, E., Williams, S.E., Zander, K.K., 2013. Using assisted colonisation to conserve biodiversity and restore ecosystem function under climate change. Biological Conservation 157, 172-177.

Maiorano, L., Falcucci, A., Zimmermann, N.E., Psomas, A., Pottier, J., Baisero, D., Rondinini, C., Guisan, A., Boitani, L., 2011. The future of terrestrial mammals in the Mediterranean basin under climate change. Philosophical Transactions of the Royal Society B: Biological Sciences 366, 2681-2692.

Martins, E.d.Q.V., Pascoal, M.M.B., Santos, J.L.E.d., 1999. Deviation algorithms for ranking shortest paths. International Journal of Foundations of Computer Science 10, 247-261.

Maxwell, S.L., Cazalis, V., Dudley, N., Hoffmann, M., Rodrigues, A.S.L., Stolton, S., Visconti, P., Woodley, S., Kingston, N., Lewis, E., Maron, M., Strassburg, B.B.N., Wenger, A., Jonas, H.D., Venter, O., Watson, J.E.M., 2020. Area-based conservation in the twenty-first century. Nature 586, 217-227.

Menéndez, R., Megías, A.G., Hill, J.K., Braschler, B., Willis, S.G., Collingham, Y., Fox, R., Roy, D.B., Thomas, C.D., 2006. Species richness changes lag behind climate change. Proceedings of the Royal Society B: Biological Sciences 273, 1465-1470.

Mitchell-Jones, A.J., Amori, G., Bogdanowicz, W., Krystufek, B., Reijinders, P.J.H., Spitzenberger, F., Stubbe, M., Thissen, J.B.M., Vorhalik, V., Zima, J., 1999. The Atlas of European Mammals. Academic Press, London.

Mokany, K., Ferrier, S., Harwood, T.D., Ware, C., Di Marco, M., Grantham, H.S., Venter, O., Hoskins, A.J., Watson, J.E.M., 2020. Reconciling global priorities for conserving biodiversity habitat. Proceedings of the National Academy of Sciences 117, 9906.

Monzón, J., Moyer-Horner, L., Palamar, M.B., 2011. Climate change and species range dynamics in protected areas. BioScience 61, $752-$ 761.

Morán-Ordóñez, A., Lahoz-Monfort, J.J., Elith, J., Wintle, B.A., 2017. Evaluating 318 continental-scale species distribution models over a 60year prediction horizon: what factors influence the reliability of predictions? Global Ecology and Biogeography 26, 371-384.

Moss, R.H., Edmonds, J.A., Hibbard, K.A., Manning, M.R., Rose, S.K., van Vuuren, D.P., Carter, T.R., Emori, S., Kainuma, M., Kram, T., Meehl, G.A., Mitchell, J.F.B., Nakicenovic, N., Riahi, K., Smith, S.J., Stouffer, R.J., Thomson, A.M., Weyant, J.P., Wilbanks, T.J., 2010. The next generation of scenarios for climate change research and assessment. Nature 463, 747-756.

Naidoo, R., Balmford, A., Ferraro, P.J., Polasky, S., Ricketts, T.H., Rouget, M., 2006. Integrating economic costs into conservation planning. Trends in Ecology \& Evolution 21, 681-687.

Pacifici, M., Foden, W.B., Visconti, P., Watson, J.E.M., Butchart, S.H.M., Kovacs, K.M., Scheffers, B.R., Hole, D.G., Martin, T.G., Akcakaya, H.R., Corlett, R.T., Huntley, B., Bickford, D., Carr, J.A., Hoffmann, A.A., Midgley, G.F., Pearce-Kelly, P., Pearson, R.G., Williams, S.E., Willis, S.G., Young, B., Rondinini, C., 2015. Assessing species vulnerability to climate change. Nature Clim. Change 5, 215-224. Parmesan, C., 2006. Ecological and evolutionary responses to recent climate change. Annual Reviews in Ecology, Evolution and Systematics 37, 637-669.

Pateman, R.M., Thomas, C.D., Hayward, S.A.L., Hill, J.K., 2015. Macro- And Micro-Climatic Interactions Can Drive Variation in Species' Habitat Associations. Global Change Biology, n/a-n/a.

Pereira, J., Saura, S., Jordán, F., 2017. Single-node vs. multi-node centrality in landscape graph analysis: key habitat patches and their protection for 20 bird species in NE Spain. Methods in Ecology and Evolution 8, 1458-1467.

Pontius, R.G., Neeti, N., 2009. Uncertainty in the difference between maps of future land change scenarios. Sustainability Science 5, 39. 
Popp, A., Calvin, K., Fujimori, S., Havlik, P., Humpenöder, F., Stehfest, E., Bodirsky, B.L., Dietrich, J.P., Doelmann, J.C., Gusti, M., Hasegawa, T., Kyle, P., Obersteiner, M., Tabeau, A., Takahashi, K., Valin, H., Waldhoff, S., Weindl, I., Wise, M., Kriegler, E., Lotze-Campen, H., Fricko, O., Riahi, K., Vuuren, D.P.v., 2017. Land-use futures in the shared socio-economic pathways. Global Environmental Change 42, $331-345$.

Potter, K.A., Arthur Woods, H., Pincebourde, S., 2013. Microclimatic challenges in global change biology. Global Change Biology 19, $2932-$ 2939.

Rayfield, B., Fortin, M.-J., Fall, A., 2011. Connectivity for conservation: a framework to classify network measures. Ecology 92, 847-858.

Rogelj, J., Meinshausen, M., Knutti, R., 2012. Global warming under old and new scenarios using IPCC climate sensitivity range estimates. Nature Climate Change 2, 248.

Rozenfeld, A.F., Arnaud-Haond, S., Hernández-García, E., Eguíluz, V.M., Serrão, E.A., Duarte, C.M., 2008. Network analysis identifies weak and strong links in a metapopulation system. Proceedings of the National Academy of Sciences 105, 18824.

Salzman, J., Bennett, G., Carroll, N., Goldstein, A., Jenkins, M., 2018. The global status and trends of Payments for Ecosystem Services. Nature Sustainability 1, 136-144.

Sanderson, B.M., Knutti, R., Caldwell, P., 2015. A Representative Democracy to Reduce Interdependency in a Multimodel Ensemble. Journal of Climate 28, 5171-5194.

Santini, L., Saura, S., Rondinini, C., 2016. Connectivity of the global network of protected areas. Diversity and Distributions 22, $199-211$.

Saura, S., Bertzky, B., Bastin, L., Battistella, L., Mandrici, A., Dubois, G., 2018. Protected area connectivity: Shortfalls in global targets and country-level priorities. Biological Conservation 219, 53-67.

Saura, S., de la Fuente, B., 2017. Connectivity as the Amount of Reachable Habitat: Conservation Priorities and the Roles of Habitat Patches in Landscape Networks, In Learning Landscape Ecology: A Practical Guide to Concepts and Techniques. eds S.E. Gergel, M.G. Turner, pp. 229-254. Springer New York, New York, NY.

Sax, D.F., Early, R., Bellemare, J., 2013. Niche syndromes, species extinction risks, and management under climate change. Trends in Ecology \& Evolution 28, 517-523.

Schloss, C.A., Nuñez, T.A., Lawler, J.J., 2012. Dispersal will limit ability of mammals to track climate change in the Western Hemisphere. Proceedings of the National Academy of Sciences 109, 8606-8611.

Scoccimarro, E., Gualdi, S., Bellucci, A., Zampieri, M., Navarra, A., 2013. Heavy Precipitation Events in a Warmer Climate: Results from CMIP5 Models. Journal of Climate 26, 7902-7911.

Settele, J., Carter, T.R., KüHn, I., Spangenberg, J.H., Sykes, M.T., 2012. Scenarios as a tool for large-scale ecological research: experiences and legacy of the ALARM project. Global Ecology and Biogeography 21, 1-4.

Settele, J., Hammen, V., Hulme, P., Karlson, U., Klotz, S., Kotarac, M., Kunin, W., Marion, G., O'Connor, M., Petanidou, T., Peterson, K., Potts, S., Pritchard, H., Pysek, P., Rounsevell, M., Spangenberg, J., Steffan-Dewenter, I., Sykes, M., Vighi, M., Zobel, M., Kühn, I., 2005. Alarm: Assessing Large-scale environmental Risks for biodiversity with tested Methods. GAIA - Ecological Perspectives for Science and Society $14,69-72$.

Spangenberg, J.H., 2007. Integrated scenarios for assessing biodiversity risks. Sustainable Development 15, 343-356.

Spangenberg, J.H., Bondeau, A., Carter, T.R., Fronzek, S., Jaeger, J., Jylhä, K., Kühn, I., Omann, I., Paul, A., Reginster, I., Rounsevell, M., Schweiger, O., Stocker, A., Sykes, M.T., Settele, J., 2012. Scenarios for investigating risks to biodiversity. Global Ecology and Biogeography 21, 5-18. 
Strassburg, B.B.N., Beyer, H.L., Crouzeilles, R., Iribarrem, A., Barros, F., de Siqueira, M.F., Sánchez-Tapia, A., Balmford, A., Sansevero, J.B.B., Brancalion, P.H.S., Broadbent, E.N., Chazdon, R.L., Filho, A.O., Gardner, T.A., Gordon, A., Latawiec, A., Loyola, R., Metzger, J.P., Mills, M., Possingham, H.P., Rodrigues, R.R., Scaramuzza, C.A.d.M., Scarano, F.R., Tambosi, L., Uriarte, M., 2019. Strategic approaches to restoring ecosystems can triple conservation gains and halve costs. Nature Ecology \& Evolution 3, 62-70.

Taylor, K.E., Stouffer, R.J., Meehl, G.A., 2011. An Overview of CMIP5 and the Experiment Design. Bulletin of the American Meteorological Society $93,485-498$.

Thuiller, W., Lafourcade, B., Engler, R., Araújo, M.B., 2009. BIOMOD - a platform for ensemble forecasting of species distributions. Ecography 32, 369-373.

Urban, M.C., 2015. Accelerating extinction risk from climate change. Science 348, 571-573.

Venter, O., Sanderson, E.W., Magrach, A., Allan, J.R., Beher, J., Jones, K.R., Possingham, H.P., Laurance, W.F., Wood, P., Fekete, B.M., Levy, M.A., Watson, J.E.M., 2016. Sixteen years of change in the global terrestrial human footprint and implications for biodiversity conservation. Nat Commun 7.

Volenec, Z.M., Dobson, A.P., 2019. Conservation value of small reserves. Conservation Biology 0.

Watson, J.E.M., Darling, E.S., Venter, O., Maron, M., Walston, J., Possingham, H.P., Dudley, N., Hockings, M., Barnes, M., Brooks, T.M., 2016. Bolder science needed now for protected areas. Conservation Biology 30, 243-248.

Williams, M.J., Musolesi, M., 2016. Spatio-temporal networks: reachability, centrality and robustness. Royal Society Open Science 3, 160196.

Xie, Z., Game, E.T., Hobbs, R.J., Pannell, D.J., Phinn, S.R., McDonald-Madden, E., 2020. Conservation opportunities on uncontested lands. Nature Sustainability 3, 9-15.

Zellweger, F., De Frenne, P., Lenoir, J., Vangansbeke, P., Verheyen, K., Bernhardt-Römermann, M., Baeten, L., Hédl, R., Berki, I., Brunet, J., Van Calster, H., Chudomelová, M., Decocq, G., Dirnböck, T., Durak, T., Heinken, T., Jaroszewicz, B., Kopecký, M., Máliš, F., Macek, M., Malicki, M., Naaf, T., Nagel, T.A., Ortmann-Ajkai, A., Petřík, P., Pielech, R., Reczyńska, K., Schmidt, W., Standovár, T., Świerkosz, K., Teleki, B., Vild, O., Wulf, M., Coomes, D., 2020. Forest microclimate dynamics drive plant responses to warming. Science 368, 772.

Zhan, J., Gurung, S., Parsa, S.P.K., 2017. Identification of top-K nodes in large networks using Katz centrality. Journal of Big Data 4, 16. 
Table 1 - The species under study, their dispersal rate $\left(D_{\max }\right)$ and the range of SAT convergence levels of $C^{s}$ SATs among the 12 climate $x$ dispersal scenarios. min, $1 Q$, med, mean, $3 Q$ and max for minimum, $1^{\text {st }}$ quartile, median, mean, $3^{\text {rd }}$ quartile and maximum (i.e. convs) convergence scores, respectively; avg $n$ for the average number of sites in SATs where at least two SATs converge in at least one period of time (i.e. |l|: $\operatorname{conv}_{i, t}^{s}>1$, for all $t$ ).

\begin{tabular}{|c|c|c|c|c|c|c|c|c|c|}
\hline species & acronym & $\begin{array}{c}D_{\max } \\
(\mathrm{km} / \mathrm{yr})\end{array}$ & $\min$ & $1 Q$ & med & mean & $3 Q$ & $\max$ & $\operatorname{avg} n$ \\
\hline Alopex lagopus & Aal & 21.48 & $1-1$ & $1-1$ & $1-1$ & $2.24-2.32$ & $1-1$ & $48-73$ & $18.00-26.75$ \\
\hline Atelerix algirus & Ala & 1.62 & $1-1$ & $2-8$ & $7-25$ & $15.39-32.79$ & $20.25-41$ & $89-195$ & $13.75-27.25$ \\
\hline Canis aureus & $\mathrm{Cau}$ & 13.50 & $1-1$ & $1-3$ & $4-8$ & $11.05-25.00$ & $11-23.25$ & $64-210$ & $17.00-37.25$ \\
\hline Cricetus cricetus & Ccr & 2.90 & $1-1$ & $1-1$ & $1-1$ & $1.00-1.00$ & $1-1$ & $1-1$ & $0.00-0.00$ \\
\hline Castor fiber & $C f i$ & 14.66 & $1-1$ & $1-1$ & $1-1$ & $1.00-1.26$ & $1-1$ & $1-7$ & $0.00-40.00$ \\
\hline Capra ibex & Cib & 0.27 & $1-1$ & $1-2$ & $3-6$ & $8.44-15.62$ & $10-21.5$ & $52-122$ & $24.50-44.00$ \\
\hline Canis lupus & $\mathrm{Clu}$ & 8.89 & $1-1$ & $1-2$ & $1-6$ & $2.99-7.63$ & $6-10.75$ & $8-60$ & $51.25-75.25$ \\
\hline Capra pyrenaica & Cpy & 1.27 & $1-1$ & $1-4$ & $4-14$ & $11.49-25.00$ & $13-33$ & $74-101$ & $17.00-35.25$ \\
\hline Dryomys nitedula & Dni & 8.89 & $1-1$ & $1-1$ & $1-1$ & $1.49-3.12$ & $1-5$ & $7-17$ & $45.25-67.25$ \\
\hline Felis silvestris & Fsy & 1.00 & $1-1$ & $1-1$ & $1-2$ & $2.15-5.50$ & $2-6$ & $16-34$ & $56.50-82.75$ \\
\hline Genneta genneta & Gge & 0.43 & $1-1$ & $1-4$ & $5-7$ & $7.90-12.05$ & $9-18.25$ & $31-58$ & $30.50-48.00$ \\
\hline Gulo gulo & Ggu & 1.69 & $1-1$ & $2-4$ & $5-11$ & $11.05-17.54$ & $18-23$ & $56-168$ & $25.75-35.75$ \\
\hline Galemys pyrenaicus & Gpy & 0.05 & $1-1$ & $1-1$ & $1-1$ & $1.76-3.00$ & $1-4$ & $7-13$ & $64.25-82.00$ \\
\hline Hespestes ichneumon & $\mathrm{Hcr}$ & 8.89 & $1-1$ & $1-1$ & $1-1$ & $2.57-4.18$ & $3-6$ & $13-21$ & $55.00-68.00$ \\
\hline Hystrix cristata & Hic & 14.66 & $1-1$ & $1-2$ & $4-5$ & $6.45-11.30$ & $9-14$ & $42-122$ & $33.50-58.25$ \\
\hline Lutra lutra & Llu & 1.79 & $1-1$ & $1-1$ & $1-1$ & $1.49-2.21$ & $1-2$ & $7-13$ & $43.50-62.75$ \\
\hline Lynx lynx & Lly & 1.25 & $1-1$ & $1-1$ & $1-1$ & $1.00-1.00$ & $1-1$ & $1-1$ & $0.00-0.00$ \\
\hline Lynx pardinus & Lpa & 1.25 & $1-1$ & $2-4$ & $5-10$ & $16.53-31.74$ & $16-35$ & $164-214$ & $13.75-23.75$ \\
\hline Lepus timidus & $L t i$ & 43.4 & $1-1$ & $1-1$ & $1-1$ & $1.00-1.00$ & $1-1$ & $1-1$ & $0.00-0.00$ \\
\hline Muscardinus avellanarius & Mav & 1.00 & $1-1$ & $1-1$ & $1-1$ & $1.00-1.00$ & $1-1$ & $1-1$ & $0.00-0.00$ \\
\hline Microtus cabrerae & Mca & 1.30 & $1-1$ & $1-1$ & $1-2$ & $2.96-5.67$ & $3-10$ & $20-25$ & $44.50-60.25$ \\
\hline Mustela lutreola & Mlu & 10.20 & $1-1$ & $1-1$ & $2-3$ & $3.77-9.39$ & $5-13$ & $22-43$ & $33.50-77.50$ \\
\hline Martes martes & Mma & 11.70 & $1-1$ & $1-1$ & $1-1$ & $1.00-1.00$ & $1-1$ & $1-1$ & $0.00-0.00$ \\
\hline Mustela putorius & Мpu & 11.70 & $1-1$ & $1-1$ & $1-1$ & $1.00-1.00$ & $1-1$ & $1-1$ & $0.00-0.00$ \\
\hline Ovis ammon & Oam & 5.84 & $1-1$ & $1-3$ & $3-6$ & $5.57-10.99$ & $7-14$ & $37-57$ & $37.50-67.75$ \\
\hline Pteromys volans & Pvo & 14.66 & $1-1$ & $1-1$ & $1-2$ & $1.00-3.15$ & $1-6$ & $1-7$ & $0.00-85.25$ \\
\hline Rupicapra rupicapra & Rru & 14.66 & $1-1$ & $1-2$ & $2-6$ & $6.92-15.27$ & $7-20$ & $44-67$ & $21.25-40.25$ \\
\hline Sicista betulina & Sbe & 0.46 & $1-1$ & $1-1$ & $1-1$ & $1.00-1.00$ & $1-1$ & $1-1$ & $0.00-0.00$ \\
\hline Spermophilus citellus & Sci & 43.4 & $1-1$ & $1-1$ & $1-1$ & $1.00-1.00$ & $1-1$ & $1-1$ & $0.00-0.00$ \\
\hline Ursus arctos & Uar & 4.12 & $1-1$ & $1-1$ & $1-1$ & $1.00-1.35$ & $1-1$ & $1-7$ & $0.00-33.50$ \\
\hline
\end{tabular}


Table 2 - Summary results for each species using four criteria (the overall outcomes of $C^{s}$ and $C / s$ SATS in EU28: criteria 1 to 6 ; the outcomes of $C^{s}$ and $C / s$ SATs within protected areas (PAs) and Natura 2000 sites (N2k): criteria 1a-13a and 1b-13b, respectively; the outcomes $C^{s}$ and $C / s$ SATs related with the human footprint index (HII): criteria 7c:13c; and sensitivity of $C^{s}$ and $C / s$ SATs to climate and dispersal scenarios: criteria 14-19. Colors evaluate outcomes on the base of negative (red), neutral or not significant (yellow) or positive (green) prospects.
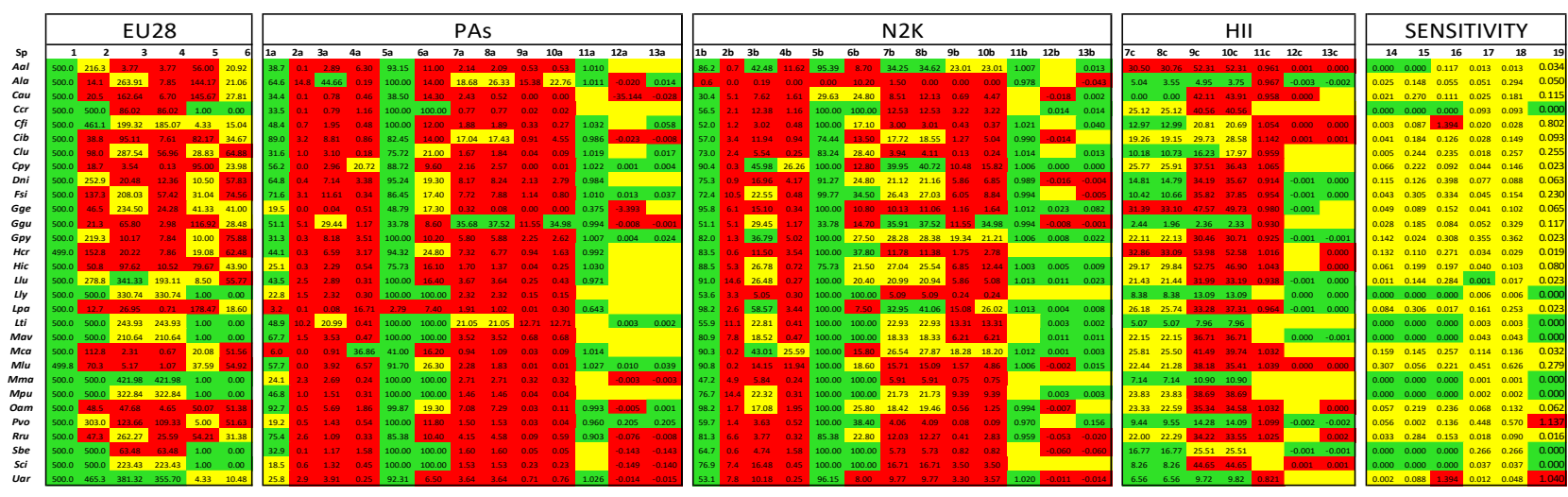

1: averaged number of Cs SATs (EU28: green: 333-500, yellow: 167-332, red: 1-166; PAs \& N2k: green: $>30 \%$ EU28, yellow: 17\%>EU28 $>30 \%$ EU28, red: $<17 \%$ EU28; HIl: green: $<17 \%$ EU28, yellow: 17\% $>$ EU28 $>30 \%$ EU28, red: $>30 \%$ EU28); 2: averaged number of C/s SATs (color coding as 1); 3 . averaged Ps (color coding as 1); 4: averaged Pls (color coding as 1); 5 : averaged max convs (EU28: green: 1, yellow: $2-50$, red: $>50$; PAs \& N2k: green: $>30 \%$ EU28, yellow: 17\%>EU28>30\% EU28, red: <17\% EU28; HII: green: <17\% EU28, yellow: 17\%>EU28>30\% EU28, red: $>30 \%$ EU28); 6 : averaged number of convergence centers i: conv $v_{i t}^{s}>1$ (EU28: green: 0, yellow: 1-50, red: $>50$; PAs \& N2k: green: $>30 \%$ EU28, yellow: 17\% >EU28>30\% EU28, red: <17\% EU28; HII: green: <17\% EU28, yellow: $17 \%>$ EU28 $>30 \%$ EU28, red: $>30 \%$ EU28); 7 : averaged \% area $C^{s}$ coverage (PAs \& N2k: green: $>30 \%$, yellow: $17 \%-30 \%$, red: <17\%; HII: green: <17\%, yellow: 17\%-30\%; red: >30\%); 8 : averaged \% area C/s coverage (color coding as 7); 9 : averaged \% $P$ s coverage (color coding as 7); 10 : averaged \% P/s coverage (color coding as 7); 11 : averaged incidence ratio rate of coverage over i: $\boldsymbol{c o n v}_{i, t}^{s}$ (PAs \& N2k: green: $>0$, yellow: 0 or not signif, red: $<0$; HIl: green: $<0$, yellow: 0 or not signf; red: $\left.>0\right)$; 12 : averaged linear regression slope of coverage over overall persistence of $C^{s} S A T s$ passing in $i, \beta_{\text {pers }}$ (color coding as 11) 13: averaged linear regression slope of coverage over overall persistence of C/s SATs passing in $i$, $\beta_{\text {pers }}$ (color coding as 11); 14: standard deviation Ps from dispersal scenarios (EU28: green: 0; yellow: 0-1; red >1); 15: standard deviation Pls from dispersal scenarios (color coding as 14); 16: standard deviation conv $v_{i, t}^{s}$ from dispersal scenarios (color coding as 14); 17: standard deviation Ps from climate scenarios (color coding as 14); 18:

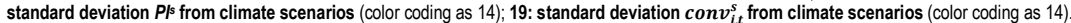


Table 3 - Mathematical notations.

\begin{tabular}{|c|c|}
\hline Notation & Meaning \\
\hline$s$ & A species from a set $S$ of species in analysis \\
\hline$i$ & A site (planning unit) from a set of $I$ of planning units in the analyzed region \\
\hline$T$ & The temporal horizon of analysis \\
\hline$c l$ & A particular climate scenario in $\{\mathrm{RCP} 4.5,5 \mathrm{CP} 6.0, \mathrm{RCP} 8.5\}$ \\
\hline$d p$ & A particular species dispersal scenario among $\{D 1, D 2, D 3, D 4\}$ \\
\hline$c$ & A SAT made of sites $\left\{i 0, i_{1}, \ldots, i T\right\}$, one per time period \\
\hline$C^{s}(c l, d p)$ (abbrev to $\left.C^{s}\right)$ & $\begin{array}{l}\text { The set of the } 500 \text { largest persistence SATs for species } s \text {, obtained using } \\
c l x d p \text { scenario }\end{array}$ \\
\hline$C / s(c l, d p)$ (abbrev to $C / s)$ & $\begin{array}{l}\text { The subset of independent SATs of } C^{s} \text { for which the sum of persistence } \\
\text { with respect to species } s \text { is maximum, obtained using } c l \times d p \text { scenario }\end{array}$ \\
\hline$o_{i, t}^{s}$ & The suitability/favorability of site $i$ at time $t$ for species $s$ \\
\hline$d_{D}^{s}$ & $\begin{array}{l}\text { An estimate of the dispersal success for species } s \text { to reach sites at } \\
\text { distance } D \text { from a general source site (see Eq. 1) }\end{array}$ \\
\hline$D_{\max }^{s}$ & $\begin{array}{l}\text { The maximum dispersal distance of species } s \text { in a time period (i.e. } d_{D}^{S}= \\
0, \text { for } D>D_{\max }^{S} \text { ) }\end{array}$ \\
\hline$D(i, j)$ & The distance between sites $i$ and $j$ \\
\hline$P_{c}^{s}(c l, d p)$ abbrev to $\left.P_{c}^{s}\right)$ & $\begin{array}{l}\text { The persistence for species } s \text { in SAT } c \text { (see Eq. 2), obtained using the } c l x \\
d p \text { scenario }\end{array}$ \\
\hline$P^{s}(c l, d p)$ (abbrev to $P(s)$ & $\begin{array}{l}\text { Species } s \text { overall persistence (i.e. the sum of persistence of SATs in } C^{s} \text {, } \\
\text { for species } s \text { ), in scenario } c l x d p \text { (see Eq. } 3 \text { ) }\end{array}$ \\
\hline$P l s(c l, d p)$ (abbrev to $\left.P^{s}\right)$ & $\begin{array}{l}\text { Species } s \text { overall independent persistence (i.e. sum of persistence of } \\
\text { independent SATs in } C l s \text {, for species } s \text { ), in scenario } c l x d p \text { (see Eq. 4) }\end{array}$ \\
\hline $\operatorname{conv}_{i, t}^{s}(c l, d p)\left(\right.$ abbrev to $\left.\operatorname{con} v_{i, t}^{s}\right)$ & $\begin{array}{l}\text { Level of SAT convergence at site } i \text { and time period } t \text { with respect to } C^{\text {s }} \text { (i.e. } \\
\text { the number of SATs of } C^{s} \text { that intersect at site } i \text { in time period } t \text { ), in scenario } \\
c l \times d p\end{array}$ \\
\hline $\max \operatorname{conv} v^{s}(c l, d p)$ (abbrev to $\left.\max c o n v^{s}\right)$ & $\begin{array}{l}\text { The level of SAT convergence associated to sets } C s(c l, d p) \text { (i.e., the largest } \\
\text { convergence level among all sites and all time-periods; } \max \text { convs } \\
=\max _{\{i, t\}} \operatorname{conv} v_{i, t}^{s} \text { ) under scenario } c l \times d p\end{array}$ \\
\hline$R E F 1^{s}(c l, d p)$ (abbrev REF1s) & $\begin{array}{l}\text { Referential sets of SATs made of the } 500 \text { fixed populations, i.e }\{c \text { : } \\
\left.i_{0}=i_{1}=i_{2}=i_{3}\right\} \text { in Eq. } 2 \text {, presenting the largest persistence scores } P_{c}^{S} \text { under } \\
\text { scenario } \mathrm{cl} x \mathrm{dp}\end{array}$ \\
\hline$\left.R E F 2^{s}(c l, d p)\right)\left(a b b r e v ~ R E F 2^{s}\right)$ & $\begin{array}{l}\text { Referential sets of SATs made of the } 500 \text { fixed populations, i.e. sites, with } \\
\text { the largest suitability scores in the baseline time period, i.e. }\left\{c: i_{0}=i_{1}=i_{2}=i_{3}\right\} \\
\text { and } o_{i 0}^{s} \text { are the } 500 \text { largest suitability scores under scenario } \mathrm{cl} \times \mathrm{dp}\end{array}$ \\
\hline
\end{tabular}


FIGURES

a) C utility

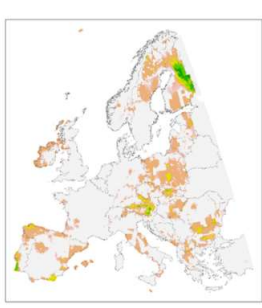

e) C utility (distr)

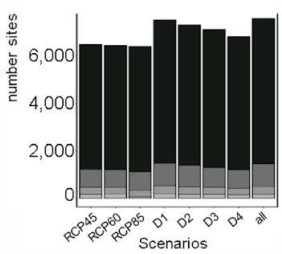

b) Cl utility

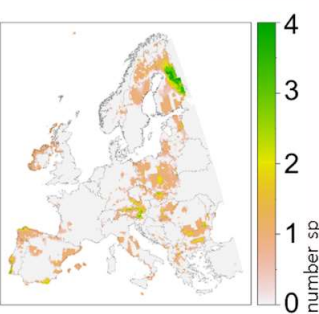

f) $\mathrm{Cl}$ utility (distr)

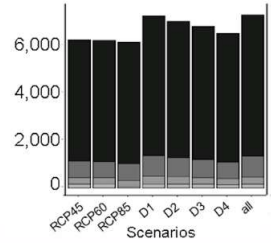

c) C centrality

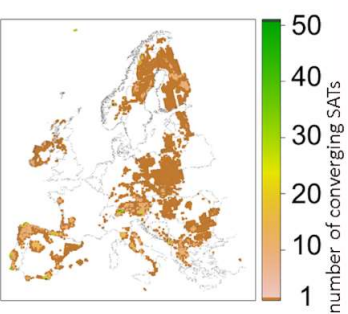

g) C centrality (distr)

d) Species richness

\begin{tabular}{cccccc}
\hline conv & base & $\mathbf{2 0 2 0}$ & $\mathbf{2 0 5 0}$ & $\mathbf{2 0 8 0}$ & all \\
\hline 1 & 6167 & 6183 & 6190 & 6230 & 6273 \\
$\mathbf{2 - 1 0}$ & 972 & 978 & 999 & 1041 & 1166 \\
$\mathbf{1 1 - 2 0}$ & 105 & 88 & 82 & 83 & 90 \\
$\mathbf{2 1 - 3 0}$ & 34 & 29 & 24 & 22 & 27 \\
$\mathbf{3 1 - 4 0}$ & 13 & 12 & 11 & 13 & 12 \\
$\mathbf{4 1 - 5 0}$ & 6 & 8 & 4 & 3 & 3 \\
$\mathbf{7 5 0}$ & 7 & 9 & $\mathbf{1 2}$ & 10 & 8 \\
\hline
\end{tabular}

1234

Figure 1 -The SATs of the thirty mammal species respecting $C^{s}$ and $C /$ s. a) and $\mathbf{b}$ ) the utility maps for each set of SATs (i.e. average number of species dispersing in each site, among the three RCP $x$ four dispersal scenarios $x$ four time periods); $c$ ) the centrality map of $C$ s (i.e. the average number of SATs among all the species converging in each site at the same time period). d) species richness maps using occurrence data from atlases; e) and f) the extent distribution of site utility levels (number of dispersing species) for $\mathrm{C}^{s}$ and $\mathrm{Cl}^{s}$, respectively: counts are made for each climate scenario, RCP8.5, RCP6.0 and RCP4.5 (average among dispersal scenarios and time periods), for each dispersal scenario, D1, D2, D3 and D4 (average among climate scenarios and time periods) and averaging all 12 scenarios and time periods (all); $g$ ) the representativeness of centrality classes in each time period (base: baseline, 2020, 2050 and 2080), averaged among the 12 climate $x$ dispersal scenarios. 


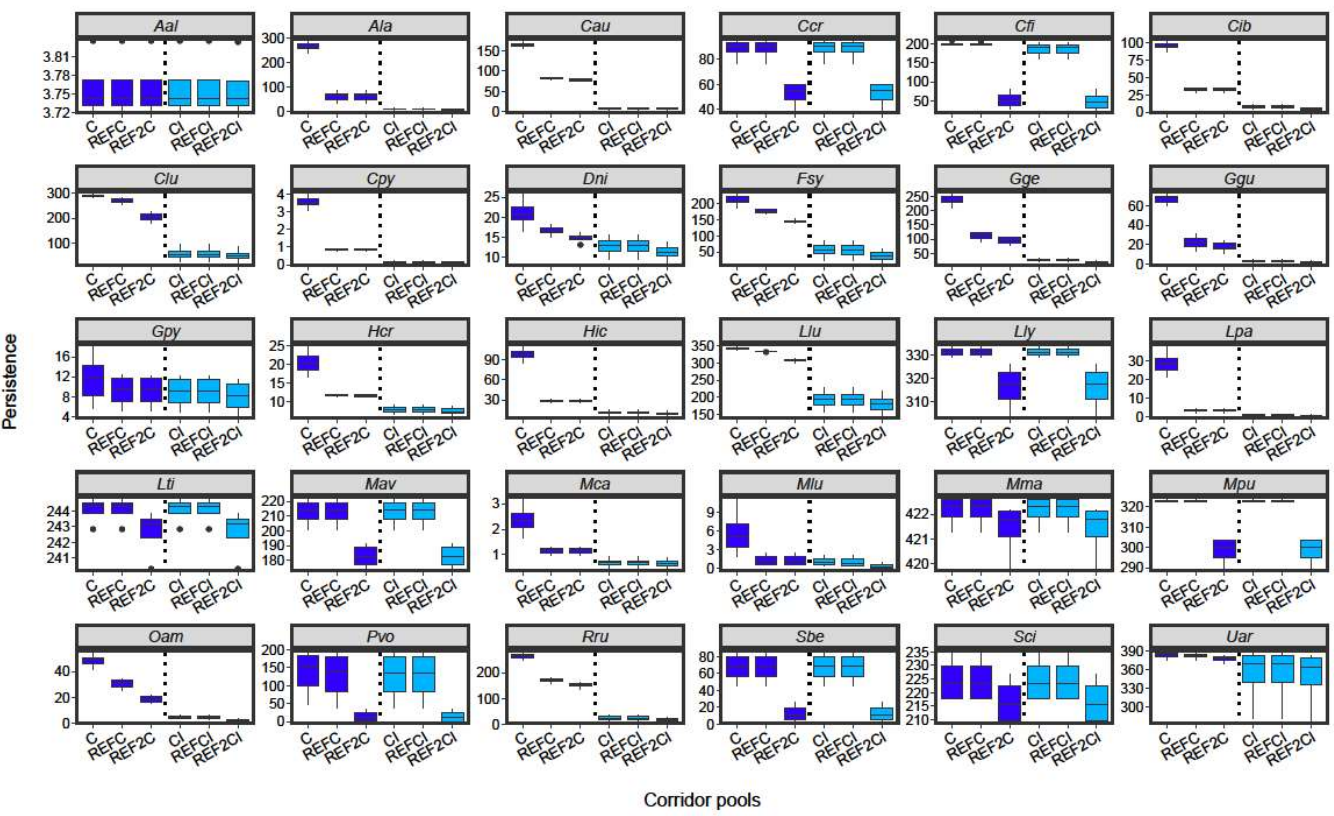

Figure 2 -Overall persistence scores of each species associated to the top-persistence unconstrained SAT sets, $\boldsymbol{C}^{s}$, the top-persistence independent SAT sets, $\mathbf{C l}^{\mathbf{s}}$, and two referential SAT sets: $R E F C^{s}$ and $R E F C / s$ represent sets of fixed SATs retrieving the largest persistence scores with the number of SATs in each set equal to the number of SATs in $C^{s}$ and $C / s$, respectively; REF2Cs and $R E F 2 C / s$ represent SATs fixed in the sites with the largest climatic suitability in the baseline period. The number of SATs in each set equal the number of SATs in $\boldsymbol{C}^{\mathbf{s}}$ and $\mathbf{C l}$, respectively. Boxplots refer to the overall persistence scores obtained from three climate $x$ four dispersal scenarios: horizontal lines depict median scores; the verticalextreme edges of boxes are the $1^{\text {st }}$ and $3^{\text {rd }}$ persistence quartiles (from bottom to top) and whiskers refer to the 1.5 interquartile ranges.

Aal: Atelerix algirus; Ala: Alopex lagopus; Cau: Canis aureus; Ccr: Cricetus cricetus; Cfi: Castor fiber; Cib: Capra ibex; Clu: Canis lupus; Cpy:Capra pyrenaica; Dni: Dryomys nitedula; Fsi: Felis silvestris; Gge: Genetta genetta; Ggu: Gulo gulo; Gpy: Galemys pyrenaicus; Hcr: Hystrix cristata; Hic: Hespestes ichneumon; Llu: Lutra lutra; Lly: Lynx lynx; Lpa: Lynx pardinus; Lti: Lepus timidus; Mav: Muscardinus avellanarius; Mca: Microtus cabrerae; Mlu: Mustela lutreola; Mma: Martes martes; Mpu: Mustela putorius; Oam: Ovis ammon; Pvo: Pteromys volans; Rru: Rupicapra rupicapra; Sbe: Sicista betulina; Sci: Spermophilus citellus; Uar: Ursus arctos. 

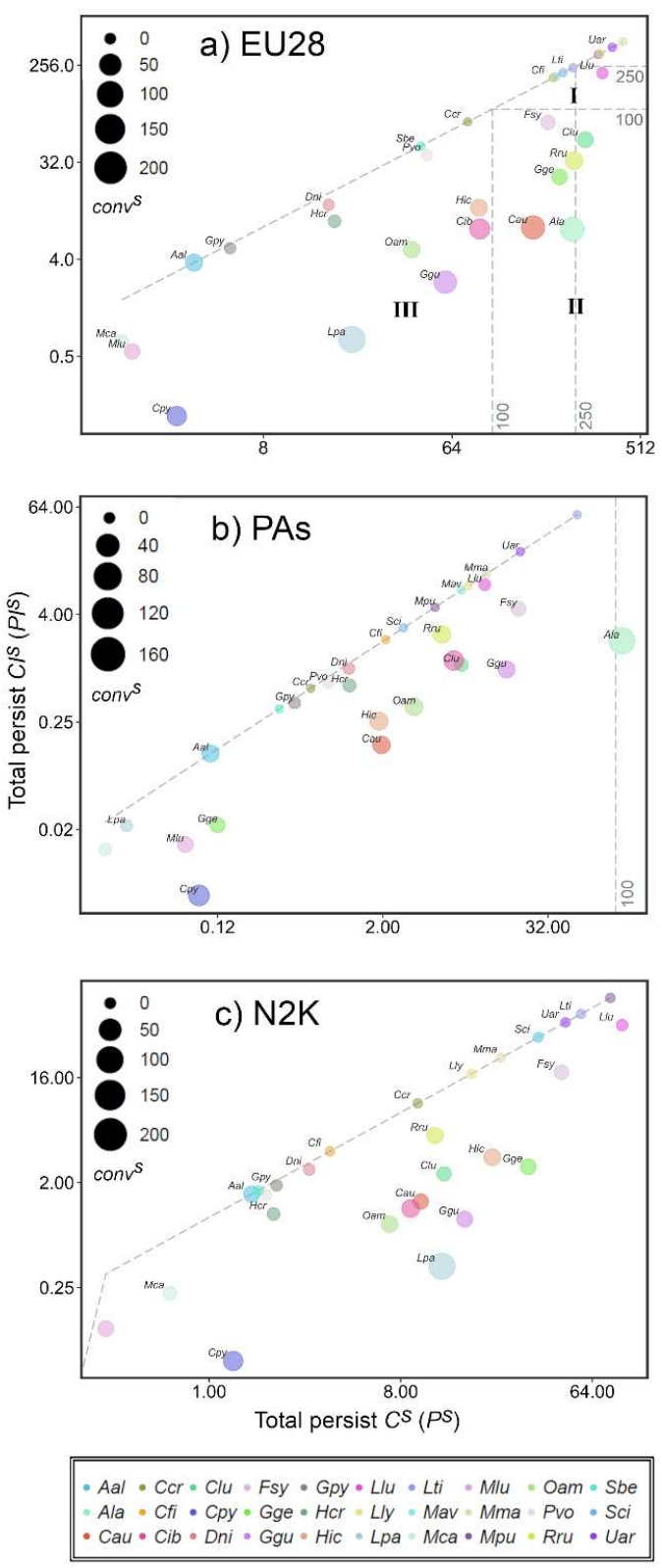

Figure 3 - Relationship between overall persistence scores $P_{s}$ associated to $C^{s}$ SATs and $P / s$ associated to $\mathrm{C} / \mathrm{s}$ SATs (log2-scaled axes) and maximum convergence levels, max convs, of $C^{s}$ SATs (circle size) for the thirty analyzed species in a) the whole Europe, EU28; b) the protected areas, PAs, and; c) the Natura 2000 sites, N2k. Because of circle proximity not all species names are presented in the graphs. Values refer to the RCP8.5 x D1 dispersal scenario. The diagonal dashed line represents equal persistence values between both SAT sets. Horizontal and vertical dotted lines represent a persistence score of 100 and 250 (i.e. $20 \%$ and $50 \%$ the maximum potential value, respectively). I, II and III define three domains of conservation evaluation.

Aal: Atelerix algirus; Ala: Alopex lagopus; Cau: Canis aureus; Ccr: Cricetus cricetus; Cfi: Castor fiber; Cib: Capra ibex; Clu: Canis lupus; Cpy:Capra pyrenaica; Dni: Dryomys nitedula; Fsi: Felis silvestris; Gge: Genetta genetta; Ggu: Gulo gulo; Gpy: Galemys pyrenaicus; Hcr: Hystrix cristata; Hic: Hespestes ichneumon; Llu: Lutra lutra; Lly: Lynx lynx; Lpa: Lynx pardinus; Lti: Lepus timidus; Mav: Muscardinus avellanarius; Mca: Microtus cabrerae; Mlu: Mustela lutreola; Mma: Martes martes; Mpu: Mustela putorius; Oam: Ovis ammon; Pvo: Pteromys volans; Rru: Rupicapra rupicapra; Sbe: Sicista betulina; Sci: Spermophilus citellus; Uar: Ursus arctos. 
a) PAs

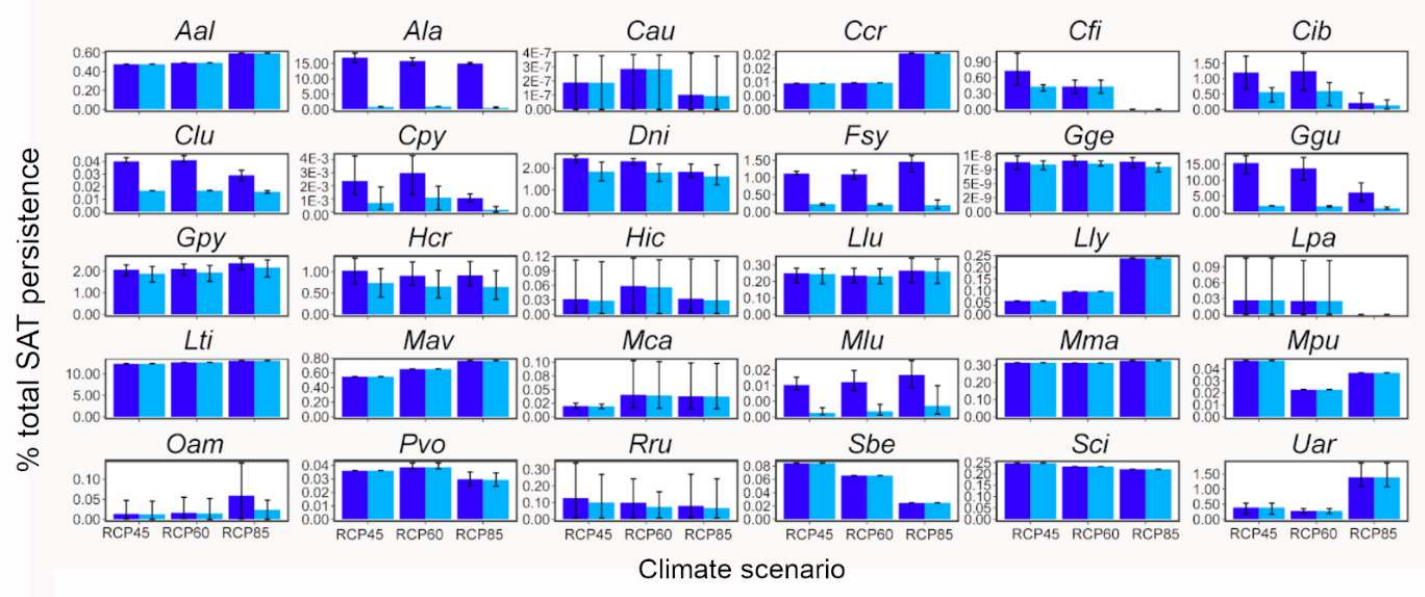

b) N2k

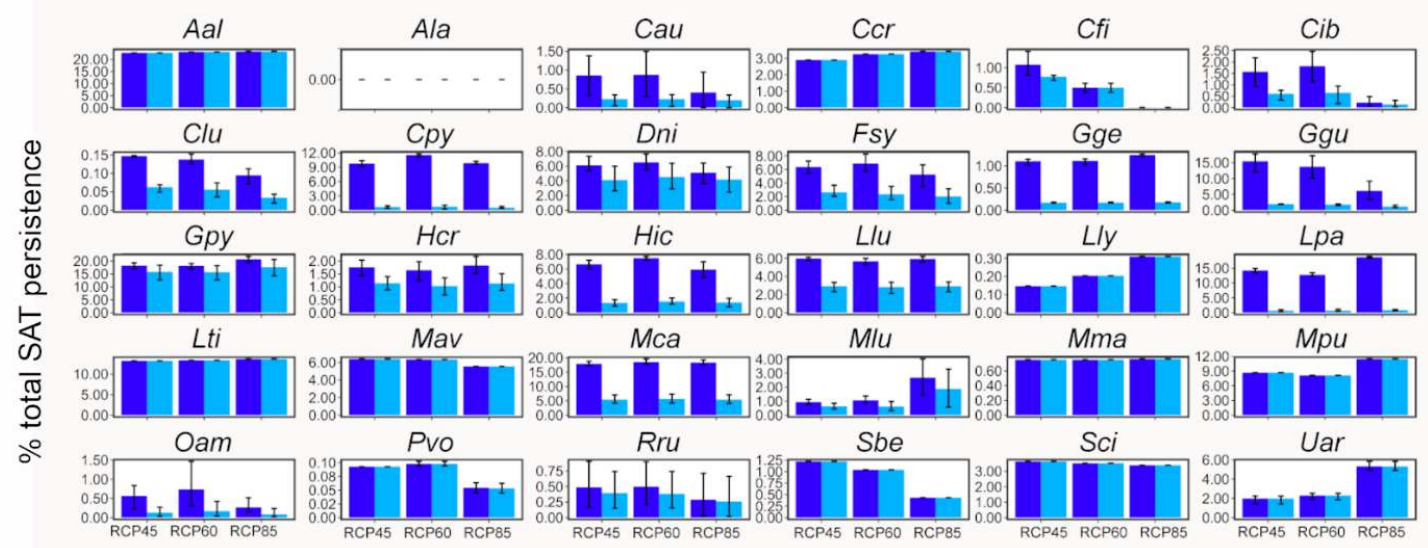

Climate scenario

Figure 4 - The percentage of overall persistence scores of each species in Cs SATs and in the respective C/s SAT-sets encompassed by conservation areas, a) nationally-designated protected areas, PAs, and b) Natura 2000 sites, N2k, under RCP4.5, RCP6.0 and RCP8.5. Error bars refer to variability (max-min values) among dispersal scenarios.

Aal: Atelerix algirus; Ala: Alopex lagopus; Cau: Canis aureus; Ccr: Cricetus cricetus; Cfi: Castor fiber; Cib: Capra ibex; Clu: Canis lupus; Cpy:Capra pyrenaica; Dni: Dryomys nitedula; Fsi: Felis silvestris; Gge: Genetta genetta; Ggu: Gulo gulo; Gpy: Galemys pyrenaicus; Hcr: Hystrix cristata; Hic: Hespestes ichneumon; Llu: Lutra lutra; Lly: Lynx lynx; Lpa: Lynx pardinus; Lti: Lepus timidus; Mav: Muscardinus avellanarius; Mca: Microtus cabrerae; Mlu: Mustela lutreola; Mma: Martes martes; Mpu: Mustela putorius; Oam: Ovis ammon; Pvo: Pteromys volans; Rru: Rupicapra rupicapra; Sbe: Sicista betulina; Sci: Spermophilus citellus; Uar: Ursus arctos. 